\title{
Implementing a sectional scheme for early aerosol growth from new particle formation in the Norwegian Earth System Model v2: comparison to observations and climate impacts
}

\author{
Sara M. Blichner ${ }^{1}$, Moa K. Sporre ${ }^{2}$, Risto Makkonen ${ }^{3,4}$, and Terje K. Berntsen ${ }^{1}$ \\ ${ }^{1}$ Department of Geosciences and Centre for Biogeochemistry in the Anthropocene, University of Oslo, Oslo, Norway \\ ${ }^{2}$ Department of Physics, Lund University, Lund, Sweden \\ ${ }^{3}$ Institute for Atmospheric and Earth System Research/Physics, Faculty of Science, University of Helsinki, \\ Helsinki, Finland \\ ${ }^{4}$ Climate System Research, Finnish Meteorological Institute, Helsinki, Finland
}

Correspondence: Sara Marie Blichner (s.m.blichner@geo.uio.no)

Received: 21 October 2020 - Discussion started: 12 November 2020

Revised: 16 March 2021 - Accepted: 1 April 2021 - Published: 4 June 2021

\begin{abstract}
Aerosol-cloud interactions contribute to a large portion of the spread in estimates of climate forcing, climate sensitivity and future projections. An important part of this uncertainty is how much new particle formation (NPF) contributes to cloud condensation nuclei (CCN) and, furthermore, how this changes with changes in anthropogenic emissions. Incorporating NPF and early growth in Earth system models (ESMs) is, however, challenging due to uncertain parameters (e.g. participating vapours), structural issues (numerical description of growth from $\sim 1$ to $\sim 100 \mathrm{~nm}$ ) and the large scale of an ESM grid compared to the NPF scale. A common approach in ESMs is to represent the particle size distribution by a certain number of log-normal modes. Sectional schemes, on the other hand, in which the size distribution is represented by bins, are considered closer to first principles because they do not make an a priori assumption about the size distribution.

In order to improve the representation of early growth, we have implemented a sectional scheme for the smallest particles (5-39.6 nm diameter) in the Norwegian Earth System Model (NorESM), feeding particles into the original aerosol scheme. This is, to our knowledge, the first time such an approach has been tried. We find that including the sectional scheme for early growth improves the aerosol number concentration in the model when comparing against observations, particularly in the 50-100 nm diameter range. Furthermore, we find that the model with the sectional scheme pro-
\end{abstract}

duces much fewer particles than the original scheme in polluted regions, while it produces more in remote regions and the free troposphere, indicating a potential impact on the estimated aerosol forcing. Finally, we analyse the effect on cloud-aerosol interactions and find that the effect of changes in NPF efficiency on clouds is highly heterogeneous in space. While in remote regions, more efficient NPF leads to higher cloud droplet number concentration (CDNC), in polluted regions the opposite is in fact the case.

\section{Introduction}

The formation of new particles in the atmosphere, known as new particle formation (NPF), occurs through the clustering and nucleation of low-volatility vapours. These particles can then influence the climate by growing via condensation to sizes at which they act as cloud condensation nuclei (CCN) (Twomey, 1974; Albrecht, 1989) - or even by interacting directly with radiation if they grow large enough (Boucher et al., 2013). NPF has received increasing attention in recent years due to the aforementioned climate impacts as well as its implications for human health. This has lead to new insights into the mechanisms involved in NPF, and subsequently new parameterization schemes have been developed and included in Earth system models (ESMs). For example, Gordon et al. (2016) showed that including a NPF pathways 
from pure organic nucleation nucleation (Kirkby et al., 2016; Riccobono et al., 2014; Gordon et al., 2017, 2016; Dunne et al., 2016; Tröstl et al., 2016) in a global aerosol model resulted in a considerable diminishing of the estimated negative forcing due to aerosol-cloud interactions since pre-industrial times $\left(+0.22 \mathrm{~W} \mathrm{~m}^{-2}, 27 \%\right)$. This result illustrates the importance of adequately representing the effects of NPF in ESMs for our understanding of historical forcing and thus climate sensitivity, especially considering that cloud-aerosol interactions are estimated to be responsible for a large fraction of the observed negative radiative forcing since pre-industrial times (Boucher et al., 2013).

In spite of NPF being the subject of a lot of research over recent years, there is still uncertainty about the species involved in both nucleation and subsequent particle growth (Kerminen et al., 2018; Lee et al., 2019). In order for NPF to be successful, particles must form and grow up to a decent size, often defined to be out of the nucleation mode, i.e. $10 \mathrm{~nm}$. Due to the Kelvin effect, only atmospheric gases with very low volatility are able to contribute to the initial steps in NPF, and in many atmospheric conditions the growth rates provided are too slow for particles to survive losses to coagulation and evaporation (Semeniuk and Dastoor, 2018). Sulfuric acid is known to be the most important species for nucleation due to its low vapour pressure, while bases such as amines and ammonia may enhance the nucleation rate (Lee et al., 2019; Kerminen et al., 2018). There is evidence that extremely low-volatility organic vapours also contribute significantly, especially in remote areas (Semeniuk and Dastoor, 2018; Dunne et al., 2016; Riccobono et al., 2014). For the subsequent growth of the particles, the Kelvin effect decreases and condensing organics of higher volatility, predominantly originating from the oxidation of biogenic volatile organic compounds (BVOCs), become more and more dominant and are essential in most environments (Riipinen et al., 2011; Tröstl et al., 2016).

During all stages of particle growth, the particles are subject to coagulation, reducing the number of particles that form and that grow to sizes at which they can act as CCN $(\sim 50 \mathrm{~nm}$ in diameter; Kerminen et al., 2012). The majority of this coagulation will occur with particles that are already in the CCN size range and thus results in a net loss of particles that could eventually act as CCN. However, when two small particles (below the CCN size range) coagulate, this contributes to growth of the combined particle, which could then become a cloud condensation nucleus (e.g. Kerminen et al., 2018; Lee et al., 2013; Schutgens and Stier, 2014). This effect, though, is only significant in highly polluted regions. The survival rate of NPF particles to CCN sizes is therefore in general dependent on competition between the particle growth rate by condensation and the coagulation sink.

The formation of new particles is tightly constrained by negative feedbacks. If NPF is high, the result will be an increase in particle number and with it an increase in the available surface area for condensation. This will lead to an in- crease in both condensation and coagulation sink, which further decreases the growth rate and increases the coagulation sink of new particles forming. The result is then a suppression of further NPF (e.g. Westervelt et al., 2014, 2013; Semeniuk and Dastoor, 2018; Carslaw et al., 2013; Kerminen et al., 2018; Schutgens and Stier, 2014). These loss processes which constrain the survival of new particles to larger sizes may in fact often be more important than the nucleation rate in itself. For example, Carslaw et al. (2013) show that the Global Model of Aerosol Processes (GLOMAP) has low sensitivity for particles larger than $50 \mathrm{~nm}$ to nucleation rate parameterizations but high sensitivity to processes affecting the coagulation loss of newly formed particles. This underlines the importance of adequately representing the processes that constrain the formation of new particles. If not we could end up with models wherein both the aerosol number concentration and $\mathrm{CCN}$ are overly sensitive to changes in emissions.

While there is a large body of work on describing when NPF happens in many individual environments, the transferal of this to a generalized context (which is what is needed for a climate model) is very uncertain. In other words, based on knowledge of what drives NPF in a specific environment it is not easy to derive a general parameterization (Kerminen et al., 2018; Lee et al., 2019).

From the perspective of an ESM, aerosols only become relevant when they approach $\sim 50 \mathrm{~nm}$ in diameter and may, depending on the conditions, act as CCN (Kerminen et al., 2012). However, because the formation of particles in this size range is highly dependent on aerosol dynamics at smaller sizes, climate models need to treat these dynamics with a sufficient degree of accuracy. Since climate models are required to run hundreds of years of simulations within a reasonable time span, this involves a trade-off between representing the physical process to the best of our scientific understanding on one hand and computational cost on the other hand.

In ESMs, it is common to use modal schemes to represent the particle size distribution - i.e. describing the distribution as the sum of some number of log-normal modes (e.g. Stier et al., 2005; Liu et al., 2005; Mann et al., 2010; Vignati et al., 2004). On the other hand, sectional schemes - in which the size distribution is represented by bins (e.g. Spracklen et al., 2005; Kokkola et al., 2008) - are in general considered closer to first principles because they do not make an a priori assumption about the size distribution. Nevertheless, modal schemes are generally favoured in ESMs because they require fewer tracers and are much cheaper computationally.

Any size-resolving aerosol scheme must have a cut-off diameter at which explicit modelling of aerosol number, growth and losses begins. One natural choice is the size of the critical cluster, around $1 \mathrm{~nm}$ (Lee et al., 2013). While this means that the entire size distribution of particles is treated, it adds disproportionate computational cost to the simulation for aerosols with a very short atmospheric lifetime (due to both growth out of the size range and high sensitivity to co- 
agulation) (see e.g. Lee et al., 2013). An alternative is to parameterize the growth and coagulation loss of particles up to a larger diameter, which is the approach used in most ESMs (Kerminen and Kulmala, 2002; Kerminen et al., 2004; Lehtinen et al., 2007; Anttila et al., 2010). These methods involve estimating the flux or the formation of particles at the cut-off diameter, be it modal or sectional, based on estimated growth rate and coagulation sink (see details in the model description).

There are several drawbacks of this approach, especially if the chosen cut-off diameter is high. The most important one is that it assumes steady state, i.e. the same constant growth rates from the particle formed up to the cut-off value, which in reality could take several time steps and long enough for conditions to change substantially (hours). A particle may form under conditions with a high growth rate, but in the time it would take for the particle to grow to the cut-off diameter, the growth rate might decrease due to an increased condensation sink by the many new particles being formed. In a model with a relatively high cut-off, this would lead to an overestimation of the growth rate of the nucleated particle, which would in turn lead to an overestimation of the formation rate at the cut-off (Olenius and Riipinen, 2017; Lee et al., 2013). Olenius and Riipinen (2017) test the effect of the cut-off diameter by explicitly modelling the formation of particles from vapour molecules to $10 \mathrm{~nm}$ diameter and find an overprediction by a factor of 2 or even orders of magnitude. Similarly, Lee et al. (2013) suggest that during nucleation events, the smallest particles $(<10 \mathrm{~nm})$ can be a significant condensation sink, thus regulating nucleation via reduced concentrations of precursors. They investigate the effects of cut-off diameter with a sectional aerosol scheme in the GISS-TOMAS model and compare a $1 \mathrm{~nm}$ cut-off with 3 and $10 \mathrm{~nm}$ cut-offs using Kerminen et al. (2004) to parameterize the survival of nucleated particles to the cut-off. They find that using a $10 \mathrm{~nm}$ cut-off leads to an overestimation of $\mathrm{CCN}$ at $0.2 \%$ supersaturation, with $10 \%-20 \%$ overestimation in the surface layer in most of the Northern Hemisphere, while the globally averaged change to $\mathrm{CCN}(0.2 \%)$ is minor. Furthermore, a $10 \mathrm{~nm}$ cut-off produces a high bias in the concentration of particles larger than $10 \mathrm{~nm}\left(N_{10}\right)$ of up to a factor of 3-5 in regions with high nucleation. In addition, they find that the $10 \mathrm{~nm}$ cut-off is sensitive to the time step.

Another drawback of a high cut-off diameter is that most of these parameterizations neglect self-coagulation within the sub-cut-off size range, which can be an important growth mechanism during intense new particle formation events. This concern is, however, taken into account in the Anttila et al. (2010) parameterization.

Finally, if the cut-off diameter is high, the time and location at which the new particles are inserted into the aerosol model may be effected since the parameterized growth would add the particles, at the cut-off size, in the same time step as they would be formed, i.e. within $\sim 0.5 \mathrm{~h}$. In reality, this growth could take several hours to days depending on loca-

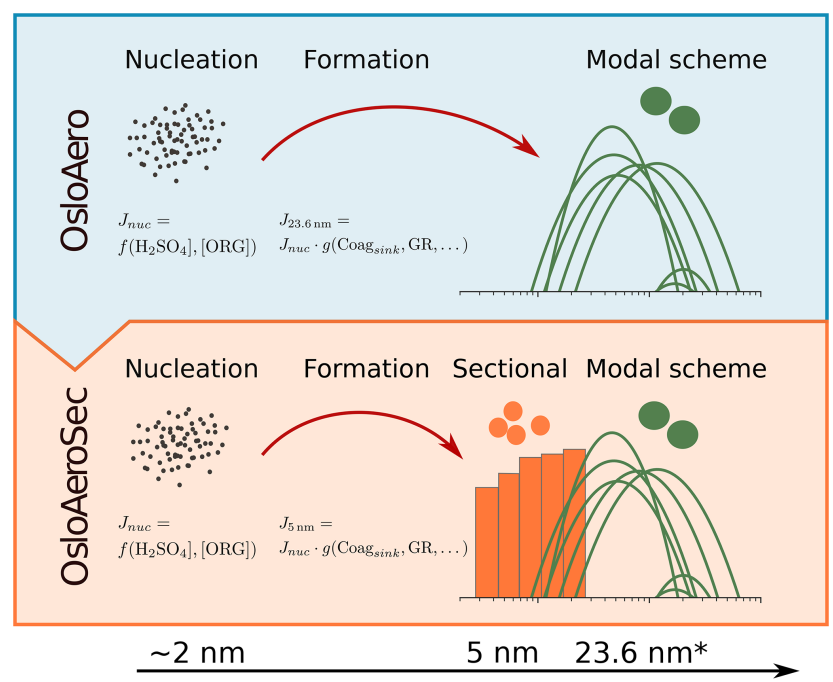

Particle diameter

Figure 1. Illustration of changes from OsloAero to OsloAeroSec. In both versions, the nucleation rate is calculated at around $2 \mathrm{~nm}$, followed by a calculation of the formation rate (the particles surviving) at 5 and $23.6 \mathrm{~nm}$ in OsloAeroSec and OsloAero, respectively, with Lehtinen et al. (2007). In OsloAero, these particles are inserted directly into the modal scheme, while in OsloAeroSec, the particles are inserted into the sectional scheme wherein they can be affected by growth and coagulation over time and space. Finally, the particles in the sectional scheme are moved from the last bin of the sectional scheme to the modal scheme. ${ }^{*} 23.6 \mathrm{~nm}$ is the number median diameter of the mode the particles from the sectional scheme are moved to, but particles are actually grown to the volume median diameter $(39.6 \mathrm{~nm})$ before they are moved to the modal scheme in order to conserve mass.

tion, at which point the air mass may have moved considerably. This is in particular the case with a high cut-off value, like in NorESM (23.6 nm) (Kirkevåg et al., 2018).

In order to improve the representation of early particle growth, we have implemented a sectional scheme for the smallest particles $(5-39.6 \mathrm{~nm}$ diameter) in the aerosol scheme in the Norwegian Earth System Model (NorESM). The sectional scheme acts as an intermediate step during NPF and feeds the grown particles into the original modal scheme. This is, to our knowledge, the first time such a hybrid approach has been attempted. The sectional scheme currently involves two condensing species (sulfuric acid and low-volatility organics) and five bins. The aerosol scheme with these changes will be referred to as OsloAeroSec. A schematic of the changes from OsloAero (the original model) to OsloAeroSec is shown in Fig. 1. The motivation is as follows.

1. In the original modal scheme in NorESM, the smallest mode has an initial number median diameter of $23.6 \mathrm{~nm}$ (volume median diameter of $39.6 \mathrm{~nm}$ ). Particles from new particle formation are inserted into this mode using the parameterization from Lehtinen et al. (2007). It 
thus does not take into account dynamics within the sub$23.6 \mathrm{~nm}$ range (e.g. competition for condensing vapours and growth of particles over more than one time step).

2. Including a sectional scheme for this size range brings the modelling of early growth closer to first principles while keeping an acceptable computational cost because the number of species involved is low. A sectional scheme within this range represents a good alternative to a nucleation mode, which is known to have problems with transferring particles to the larger mode due to the addition of new particles reducing the median diameter of the mode.

In the following we start by describing the aerosol scheme in NorESM (Sect. 2.1) and then the newly implemented sectional scheme for early growth (Sect. 2.2). Next, in Sect. 4.1, we show that the new scheme leads to improvements in the CCN-relevant particle number concentration and size distribution when compared to observational data from Asmi et al. (2011a) consisting of 24 stations in Europe and compiled as part of the EUSAAR project. Finally, we present the global changes in the state of aerosols and following cloud properties in the model with the new scheme (OsloAeroSec) compared to the original model (Sect. 4.2).

\section{Model description}

We start by briefly describing the Norwegian Earth System Model (NorESM) in general before giving a detailed description of its default aerosol model, OsloAero, in Sect. 2.1. After this, in Sect. 2.2, we will describe what changes to said aerosol scheme have been introduced in OsloAeroSec. In general, the aerosol scheme after NPF and early growth is left as it is. The only exception to this is that we have also included some changes to the diurnal variability of $\mathrm{OH}$, as described in Sect. 2.3.

The Norwegian Earth System Model version 2 (NorESM2) (Seland et al., 2020b; Bentsen et al., 2013; Kirkevåg et al., 2013; Iversen et al., 2013) is largely based on the Community Earth System Model (CESM) version 2 (Danabasoglu et al., 2020; Neale et al., 2012). The aerosol scheme in CESM2 is replaced by OsloAero6 (described below) (Kirkevåg et al., 2018), and the atmospheric component is thus named CAM6-Nor. Furthermore, the ocean model in CESM2 is replaced by the Bergen Layered Ocean Model (BLOM) (Seland et al., 2020b), though this is not used in this study as all simulations are run with prescribed sea surface temperature (SST) and sea ice concentrations. The land model is, as in CESM2, is the Community Land Model (CLM) version 5 (Lawrence et al., 2019).

\subsection{OsloAero: aerosol scheme in NorESM}

The aerosol scheme in NorESM, OsloAero, is a productiontagged aerosol model. The most notable difference to other aerosol models is that the aerosol mass is divided into "background" tracers and "process" tracers. The background tracers form log-normal modes which decide the number concentration, while the process tracers alter this initial log-normal distribution and their chemical composition. Examples of background tracers are dust, sea salt and particles from NPF, while examples of process tracers are sulfate condensate, sulfate coagulate and organic condensate. After the process tracers are applied, the resulting distribution of the "mixtures" is not (necessarily) log-normal anymore. The mass of the tracers is tracked, and the size distributions for cloud activation and optical properties are calculated using a look-up table approach (Kirkevåg et al., 2018).

\subsubsection{Chemistry}

CAM6-Nor has a simplified chemistry scheme for sulfur and organic species using the chemical pre-processor MOZART (Emmons et al., 2010). Pre-calculated monthly mean oxidant fields consisting of $\mathrm{OH}, \mathrm{O}_{3}, \mathrm{NO}_{3}$ and $\mathrm{HO}_{2}$ are read from a file (for discussion see Karset et al., 2018).

Condensing tracers in the model are $\mathrm{H}_{2} \mathrm{SO}_{4}$ and two tracers of organics produced by the oxidation of BVOCs, low-volatility organics $\left(\mathrm{SOAG}_{\mathrm{LV}}\right)$ and semi-volatile organics $\left(\mathrm{SOAG}_{\mathrm{SV}}\right)$. The model treats both organic tracers as nonvolatile during condensation but represents the volatility by separating which processes each tracer can contribute to: $\mathrm{SOAG}_{\mathrm{LV}}$ can contribute to new particle formation (NPF) and early growth, while SOAG $\mathrm{SV}$ only contributes to condensational growth.

$\mathrm{H}_{2} \mathrm{SO}_{4}$ is emitted directly or produced from oxidation of $\mathrm{SO}_{2}$ by $\mathrm{OH}$ or aqueous-phase oxidation by $\mathrm{H}_{2} \mathrm{O}_{2}$ and $\mathrm{O}_{3}$ (Tie et al., 2001). $\mathrm{SO}_{2}$ is either emitted directly or produced by oxidation of dimethyl sulfate (DMS). The condensing organic tracers, $\mathrm{SOAG}_{\mathrm{LV}}$ and $\mathrm{SOAG}_{\mathrm{SV}}$, are formed from oxidation isoprene and monoterpenes. The emissions of isoprene and monoterpene are calculated online in each time step using the Model of Emissions of Gases and Aerosols from Nature version 2.1 (MEGAN2.1) (Guenther et al., 2012), which is incorporated into CLM5. The atmospheric tracer includes only one tracer for monoterpenes, and thus the emissions of 21 monoterpene species from MEGAN2.1 are lumped together (Kirkevåg et al., 2018). In addition, production of methanesulfonic acid (MSA) by oxidation of DMS is taken into account, but since the model lacks a tracer for MSA, $20 \%$ of the MSA is put in the $\mathrm{SOAG}_{\mathrm{LV}}$ tracer and $80 \%$ in the SOAG SV.

For a complete overview of reactions and reaction rates, see Table 2 in Karset et al. (2018).

\subsubsection{Condensation}

The following is a description of the condensation routine in chronological order within one time step. The production rate, $P_{\text {gas }}$, of a condensing gas is calculated in the gas-phase 
chemistry (Sect. 2.1.1), and the condensation sink, $L_{\text {cond }}$ $\left[1 \mathrm{~s}^{-1}\right]$, is calculated based on the surface area of the background aerosols. Finally, using the initial concentration of the gas, $C_{\text {old }}$, from the previous time step, an intermediate concentration, $C_{\text {int }}$, is derived by solving the discrete Euler backwards equation:

$$
\begin{aligned}
& \frac{C_{\mathrm{int}}-C_{\mathrm{old}}}{\Delta t}=P_{\mathrm{gas}}-L_{\mathrm{cond}} C_{\mathrm{int}}, \\
& C_{\mathrm{int}}=\frac{C_{\mathrm{old}}+P_{\mathrm{gas}} \Delta t}{1+L_{\mathrm{cond}} \Delta t} .
\end{aligned}
$$

This intermediate concentration is then used in the formation of new particles (described in the next section). The NPF subroutine returns an intermediate nucleated mass loss rate, $J_{m, \text { nuc }}$. This nucleated mass is then used to calculate a nucleation loss rate, $L_{\text {nuc }}\left[1 \mathrm{~s}^{-1}\right]$.

$L_{\mathrm{nuc}}=\frac{J_{m, \mathrm{nuc}}}{C_{\mathrm{int}}}$

The new gas concentration, $C_{\text {new }}$, is calculated by solving the discrete Euler backwards equation again, including the loss rate to nucleation.

$C_{\text {new }}=\frac{C_{\text {old }}+P_{\text {gas }} \Delta t}{1+L_{\text {cond }} \Delta t+L_{\text {nuc }} \Delta t}$

Finally, the total gas lost to condensation and nucleation, $\Delta C$, is calculated as follows.

$C_{\text {new }}-C_{\text {old }}=P_{\text {gas }} \Delta t-\Delta C$

$\Delta C=P_{\text {gas }} \Delta t+C_{\text {old }}-C_{\text {new }}$

This condensate and/or nucleate, $\Delta C$, is then transferred to the corresponding process tracer for condensate of the species (e.g. sulfur condensate) and the background tracer for new particle formation particles. The mass transfer is done based on their relative contribution to the total loss rate - i.e. the fraction that is moved to the NPF tracer is $f_{\text {nuc }}=L_{\text {nuc }} /\left(L_{\text {nuc }}+L_{\text {cond }}\right)$ and the fraction to condensation is $f_{\text {cond }}=1-f_{\text {nuc }}$.

\subsubsection{New particle formation}

The tracers contributing to NPF are $\mathrm{H}_{2} \mathrm{SO}_{4}$ and organics (see Makkonen et al., 2014). As mentioned above, $\mathrm{SOAG}_{\mathrm{SV}}$ does not contribute to new particle formation. In addition, only half of the $\mathrm{SOAG}_{\mathrm{LV}}$ concentration in each time step is assumed to be low-volatility enough to contribute, and this fraction will be denoted as ELVOC in the following. The nucleation rate is parameterized with Vehkamäki et al. (2002) for binary sulfuric acid-water nucleation in the entire atmosphere, and, in addition, Eq. (18) from Paasonen et al. (2010) is added to represent boundary layer nucleation. The Paasonen et al. (2010, Eq. 18) parameterization is as follows:

$$
J_{\text {nuc }}=\mathrm{A}_{1}\left[\mathrm{H}_{2} \mathrm{SO}_{4}\right]+A_{2}[\text { ELVOC }] \text {, }
$$

where $J_{\text {nuc }}\left[1 \mathrm{~s}^{-1}\right]$ is the nucleation rate, $A_{1}=6.1 \times 10^{-7} \mathrm{~s}^{-1}$ and $A_{2}=3.9 \times 10^{-8} \mathrm{~s}^{-1}$. This is the default nucleation equation in OsloAero and is changed in OsloAeroSec - see Sect. 2.2.1.

The survival of particles from nucleation at $d_{\text {nuc }} \approx 2 \mathrm{~nm}$, to the background mode holding the NPF particles with number median diameter $23.6 \mathrm{~nm}$, is parameterized by Lehtinen et al. (2007). The formation rate, $J_{d_{\text {mode }}}$, of particles at the smallest mode is calculated by

$J_{d_{\text {mode }}}=J_{\text {nuc }} \exp \left(-\gamma d_{\text {nuc }} \frac{\operatorname{CoagS}\left(d_{\text {nuc }}\right)}{\mathrm{GR}}\right)$,

where $d_{\text {nuc }}$ is the diameter of the nucleated particle, $\operatorname{CoagS}\left(d_{\text {nuc }}\right)$ is the coagulation sink of the particles $\left[\mathrm{h}^{-1}\right]$, GR is the growth rate $\left[\mathrm{nm} \mathrm{h}^{-1}\right.$ ] of the particle (from $\mathrm{H}_{2} \mathrm{SO}_{4}$ and ELVOC, calculated using Eq. 21 from Kerminen and Kulmala, 2002), and $\gamma$ is a function of $d_{\text {mode }}$ and $d_{\text {nuc }}$ :

$\gamma=\frac{1}{m+1}\left[\left(\frac{d_{\text {mode }}}{d_{\text {nuc }}}\right)^{(m+1)}-1\right], \quad m=-1.6$.

Furthermore, $\operatorname{CoagS}\left(d_{\text {nuc }}\right)$ is calculated from CoagS $\left(d_{\text {mode }}\right)$ assuming a power-law dependency on diameter, $\operatorname{CoagS}\left(d_{\text {nuc }}\right)=\operatorname{CoagS}\left(d_{\text {mode }}\right) \cdot\left(\frac{d_{\text {nuc }}}{d_{\text {mode }}}\right)^{m}$ (Lehtinen et al., 2007, Eq. 5).

Since Kirkevåg et al. (2018), we have developed an improvement to the new particle formation rate (also used in Sporre et al., 2019, 2020). The CoagS $\left(d_{\text {nuc }}\right)$ previously included only coagulation onto accumulation- and coarsemode particles, but we amended this to include coagulation onto all pre-existing particles. This modification gives a lower and more realistic survival rate of particles from formation at 2 to $23.6 \mathrm{~nm}$.

\subsubsection{Coagulation}

OsloAero takes into account coagulation between Aitkenmode and accumulation-mode particles and between Aitkenmode and coarse-mode particles, with coagulation coefficients from the Fuchs form for Brownian diffusion (Sect. 12.3 in Seinfeld and Pandis, 1998). Technically, a normalized coagulation sink is calculated for each relevant combination of background modes, assuming some fixed prior growth by condensation and/or coagulation. To compute the normalized coagulation sink, the size distribution is split into 44 bins for the coagulation receiver mode (the larger particle), and a coagulation sink with each bin is calculated and normalized by the number concentration. This way, the normalized coagulation sink only has to be computed once. In addition, coagulation of aerosols with cloud droplets is estimated. See Seland et al. (2008) for more details.

\subsection{OsloAeroSec: new sectional scheme}

The purpose of introducing the sectional scheme is to get a more realistic growth and loss dynamic within the small- 
est aerosol sizes, with the aim of better modelling aerosolclimate effects. These smallest particles have insignificant effects on climate directly, but rather play a role through how they affect the size distribution of the larger particles. For this reason, we do not let the aerosols in the sectional scheme directly affect the radiation and cloud parameterizations, but rather consider only how new particle formation through nucleation, condensation and coagulation affects the larger aerosols in the modal scheme.

The sectional scheme currently consists of five bins (though this is flexible), and the bin sizes are set according to a discrete geometric distribution - the volume-ratio distribution (Jacobson, 2005, Sect. 13.3) - as follows: let $d_{1}, d_{2}, \ldots, d_{5}$ be the diameter for each bin and $v_{1}, v_{2}, \ldots, v_{5}$ be the volume per particle for each bin. Each particle in the bin is assumed to have this same volume (Jacobson, 2005). The volume-ratio distribution ensures that the volume per particle ratio between adjacent bins is fixed; i.e.

$r_{v}=\frac{v_{i+1}}{v_{i}}$

is fixed. This means that the ratio between the diameter in adjacent bins, $r_{\mathrm{d}}$, will be

$r_{\mathrm{d}}=\frac{d_{i+1}}{d_{i}}=\left(r_{v}\right)^{1 / 3}$

Particles are moved into the original aerosol scheme in the NPF background mode when they reach $d_{\max }=39.6 \mathrm{~nm}$, which is the volume median diameter of this mode. The volume median diameter is chosen to preserve both number and mass of the particles. Note that $d_{\max }$ is the diameter at which the particles are moved to the modal scheme. The choice of $d_{\text {min }}$, the smallest diameter bin, is flexible, and we have chosen $5 \mathrm{~nm}$ here. So for number of bins, $N$,

$r_{\mathrm{d}}=\left(\frac{d_{\mathrm{max}}}{d_{\min }}\right)^{\frac{1}{N}}$,

where $d_{\max }=39.6 \mathrm{~nm}, d_{\min }=5 \mathrm{~nm}$ and $N=5$.

The sectional scheme includes condensation from two precursors, $\mathrm{H}_{2} \mathrm{SO}_{4}$ and $\mathrm{SOAG}_{\mathrm{LV}}$, while $\mathrm{SOAG}_{\mathrm{SV}}$ is considered to not have low enough volatility to contribute. This gives a total of $N$ (number of bins) $\times 2$ tracers for the model to keep track of, keeping computational costs reasonable.

\subsubsection{Nucleation}

Nucleation is still parameterized with Vehkamäki et al. (2002) for binary sulfuric acid-water nucleation in the entire atmosphere, and the boundary layer nucleation has been updated from Paasonen et al. (2010, Eq. 18) (see Eq. 7) to Riccobono et al. (2014):

$J_{\text {nuc }}=A_{3}\left[\mathrm{H}_{2} \mathrm{SO}_{4}\right]^{2}[$ ELVOC $]$

where $A_{3}=3.27 \times 10^{-21} \mathrm{~cm}^{6} \mathrm{~s}^{-1}$.
The update was done due to the Riccobono et al. (2014) parameterization being based on more recent research and due to the fact that NPF was too high and lasted too long compared to observations with the Paasonen et al. (2010) parameterization in CAM6-NOR. Note that even though it is likely that the Riccobono et al. (2014) parameterization represents an improvement compared to Paasonen et al. (2010), large uncertainties remain due to the fact that the Riccobono et al. (2014) parameterization was developed based on an ELVOC precursor (pinanediol), rather than actual ELVOC measurements, and that it does not take into account other factors that have been shown to be of importance, like temperature and ammonia (see e.g. Semeniuk and Dastoor, 2018).

The rate at which particles are introduced into the smallest bin, $J_{d_{\min }}$, is still parameterized with Eq. (8) defined above (Lehtinen et al., 2007), but with $d_{\text {form }}=d_{\min }$ so that the cutoff size is smaller than before.

\subsubsection{Condensation}

The condensation is done in the same way as for OsloAero6, except that the calculated loss rate to condensation $L_{\text {cond }}$ is now the sum of loss to condensation onto the background modes from OsloAero and the condensation onto the sectional bins, $L_{\text {cond }}=L_{\text {cond,modes }}+L_{\text {cond,sec }}$, in Eqs. (2) and (4). Furthermore, the total gas lost, $\Delta C$, calculated by Eq. (6), is then distributed as follows.

$$
\begin{aligned}
& f_{\text {nuc }}=\frac{L_{\text {nuc }}}{L_{\text {nuc }}+L_{\text {cond,modes }}+L_{\text {cond,sec }}} \\
& f_{\text {cond,sec }}=\frac{L_{\text {cond,sec }}}{L_{\text {nuc }}+L_{\text {cond,modes }}+L_{\text {cond,sec }}} \\
& f_{\text {cond,modes }}=\frac{L_{\text {cond,modes }}}{L_{\text {nuc }}+L_{\text {cond,modes }}+L_{\text {cond,sec }}}
\end{aligned}
$$

Here, $f_{\text {nuc }}+f_{\text {cond,sec }}+f_{\text {cond,modes }}=1$. In other words, the condensate added to the modes is $C_{\text {lost,tot }} \cdot f_{\text {cond,modes. }}$ In the same fashion, condensing mass to the sectional scheme is distributed to the different bins by the strength of their respective condensational sinks,

$f_{\text {bin }\left(d_{i}\right)}=f_{\text {cond,sec }} \cdot \frac{L_{\text {cond,bin }\left(d_{i}\right)}}{L_{\text {cond,sec }}}$,

so that the condensate added to any bin, $d_{i}$, is equal to $\Delta C$.

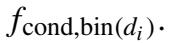

Finally, the condensational growth of particles within the sectional scheme is done in a quasi-stationary structure (Jacobson, 1997), meaning the particles grow in volume but are fitted back onto the full stationary grid between each time step (Jacobson, 2005, Sect. 13.3). This is done by assuming that (1) the total volume is constant before and after the transfer between the bins, and (2) the total number is the same. Let $v_{i}$ and $v_{i+1}$ be the volume of a particle in bin $i$ and the next bin, $i+1$, prior to any growth. Let $v_{i}^{\prime}$ be the volume of a particle in bin $i$ after growth. Furthermore, let $N_{i}$ be the number 
of particles in bin $i$ prior to growth and $\Delta N_{i+1}$ be the number of particles moved to the next bin $i+1$. Since we do not have any evaporating species, we can easily solve the equation conserving both the number and volume of aerosol for each species:

$v_{i}^{\prime} N_{i}=v_{i}\left(N_{i}-\Delta N_{i+1}\right)+v_{i+1} \Delta N_{i+1}$,

and solving for $\Delta N_{i+1}$ gives

$\Delta N_{i+1}=N_{i} \cdot \frac{v_{i}^{\prime}-v_{i}}{v_{i+1}-v_{i}}$.

After the particle mass is moved in this way, the freshly nucleated particles from the same time step are added to the smallest bin. The rationale behind this is that the nucleated particles in the same time step do not take part in the condensation sink calculation, and thus including them before the redistribution of mass on the sectional grid would only imply adding particles with no added condensate.

The time step within the nucleation and condensation code is locally divided in two compared to the rest of the code (thus $15 \mathrm{~min}$ ), and if the particles in the sectional scheme grow fast enough to skip a bin, the time step is further divided in two until it is small enough.

\subsubsection{Coagulation}

In addition to the unchanged coagulation in the original OsloAero scheme (see Sect. 2.1.4), we calculate the coagulation sink of the sectional particles onto all larger particles. This is done in the same way between particles in the original OsloAero scheme, in that a normalized coagulation sink is calculated for each background mode by dividing the size distribution into 44 bins. When sectional particles coagulate with particles in the "modal" scheme, their mass is transferred to the corresponding process tracer for condensate. This is done for simplicity and because the alternative would be to place them in the coagulation tracers - one of the process tracers - in the original scheme, which will only contribute to changes in the larger particles.

In addition to this, coagulation between the particles in the sectional scheme is taken into account. When two particles in the sectional scheme collide, this results in the loss of the particle in the smaller bin and the addition of mass to the particle in the larger bin. After this is done in each time step, the mass in the sectional scheme is redistributed in the same way as after condensation (see previous section).

\subsection{Chemistry: changes to oxidant diurnal variation}

The oxidant concentrations of the hydroxyl radical $(\mathrm{OH})$, nitrate radical $\left(\mathrm{NO}_{3}\right)$, hydroperoxy radical $\left(\mathrm{HO}_{2}\right)$ and ozone $\left(\mathrm{O}_{3}\right)$ in the model are prescribed by 3D monthly mean fields (see Seland et al., 2020b). On top of this, a diurnal cycle is applied to $\mathrm{OH}, \mathrm{HO}_{2}$ and $\mathrm{NO}_{3}$. In the default version of the model, the diurnal cycle for $\mathrm{OH}$ is basically a step function based on whether it is before or after sunrise. Since $\mathrm{OH}$ in particular is very important for the diurnal cycle of $\mathrm{H}_{2} \mathrm{SO}_{4}$, this leads to more or less a step function in $\mathrm{H}_{2} \mathrm{SO}_{4}$ concentrations as well, which is not very realistic in terms of NPF. We therefore implemented a simple sine shape to the daily variation in place of the step function.

\section{Model simulations and output post-processing}

\subsection{Simulation description}

In the following analysis we include simulations with three versions of the CAM6-Nor.

- A simulation with OsloAeroSec, referred to simply as "OsloAeroSec" (see Sect. 2.2)

- A simulation with the default version of OsloAero (see Sect.2.1), referred to as "OsloAero def "

- A simulation with the default version of OsloAero, but with the same changes to the nucleation rate (Eq. 13) and oxidants (see Sect. 2.3) as OsloAeroSec, referred to as "OsloAero imp"

The last simulation, OsloAero ${ }_{\text {imp }}$, is added in order to separate the changes made in OsloAeroSec to the nucleation rate and the diurnal concentration in the oxidants (described above) from the effect of adding a sectional scheme. The simulation characteristics are also summarized in Table 1.

NorESM2 is run with CAM6-Nor (release-noresm2.0.1, https://github.com/NorESMhub/NorESM, last access: 28 May 2021; Kirkevåg et al., 2018) coupled to the Community Land Model version 5 (CLM5) (Lawrence et al., 2019) in BGC (biogeochemistry) mode and prognostic crops. We use a $1.9^{\circ}$ (latitude) $\times 2.5^{\circ}$ (longitude) resolution grid with 32 height levels from the surface to $\sim 2.2 \mathrm{hPa}$ in hybrid sigma coordinates. We use prescribed sea surface temperature (SST) and sea ice concentrations at $1.9 \times 2.5^{\circ}$ resolution (Hurrell et al., 2008). Simulations are run from 2007 to and throughout 2014 with CMIP6 historical emissions and greenhouse gas concentrations (Seland et al., 2020b) as well as nudged meteorology (horizontal wind and surface pressure) to ERA-Interim (ECMWF, 2011) using a relaxation time of $6 \mathrm{~h}$ (Kooperman et al., 2012) (as described in Karset, 2020, Sect. 4.1). The year 2007 is discarded as spin-up. The initial conditions for all simulations are taken from a simulation with CAM6-Nor run from 2000 and throughout 2006.

\subsection{Post-processing of model output}

All figures, except comparisons to observations (described below), are produced from monthly mean output files from the model. When we present figures showing averaged values over maps, these are either column burdens or "near-surface" 
Table 1. Simulation overview. See the detailed description in Sect. 3.

\begin{tabular}{llll}
\hline Simulation & Nucleation parameterization & Oxidant treatment & Early growth treatment \\
\hline OsloAeroSec & $\mathrm{A}_{3}\left[\mathrm{H}_{2} \mathrm{SO}_{4}\right]^{2} \times{\text { [ELVOC }]^{\mathrm{a}}}^{\mathrm{a}}$ & Improved diurnal variation & Lehtinen et al. (2007) + sectional scheme \\
OsloAero $_{\text {imp }}$ & $\mathrm{A}_{3}\left[\mathrm{H}_{2} \mathrm{SO}_{4}\right]^{2} \times{\text { [ELVOC }]^{\mathrm{a}}}^{\mathrm{b}}$ & Improved diurnal variation & Lehtinen et al. (2007) \\
OsloAero $_{\text {def }}$ & $\mathrm{A}_{1}\left[\mathrm{H}_{2} \mathrm{SO}_{4}\right]+\mathrm{A}_{2}[\mathrm{ELVOC}]^{\mathrm{b}}$ & Default diurnal variation & Lehtinen et al. (2007) \\
\hline
\end{tabular}

$\mathrm{A}_{1}=6.1 \times 10^{-7} \mathrm{~s}^{-1} \cdot \mathrm{A}_{2}=3.9 \times 10^{-8} \mathrm{~s}^{-1} . \mathrm{A}_{3}=3.27 \times 10^{-21} \mathrm{~cm}^{6} \mathrm{~s}^{-1}$. ${ }^{\mathrm{a}}$ Riccobono et al. (2014). ${ }^{\mathrm{b}}$ Paasonen et al. (2010).

Table 2. Region overview. These regions are used to create vertical average profiles.

\begin{tabular}{llll}
\hline Region name & Description & Latitude & Longitude \\
\hline Continental & Grid boxes with $>50 \%$ land & & \\
Marine & Grid boxes with $<50 \%$ land & & \\
Global & & & \\
Polar N & & $66.5-90^{\circ} \mathrm{N}$ & $180^{\circ} \mathrm{W}-180^{\circ} \mathrm{E}$ \\
Polar S & & $66.5-90^{\circ} \mathrm{S}$ & $180^{\circ} \mathrm{W}-180^{\circ} \mathrm{E}$ \\
Amazonas & & $16^{\circ} \mathrm{S}-2^{\circ} \mathrm{N}$ & $74-50^{\circ} \mathrm{W}$ \\
\hline
\end{tabular}

averages of the variable in question. The near-surface averages are calculated as the average of all grid cells below $850 \mathrm{hPa}$, weighted by the grid cell pressure thickness to account for the mass in the grid cell. Cloud radiative effects and direct radiative effects are calculated as described in Ghan (2013).

For the model-to-model comparisons, we include an analysis of whether the change is significant. Dots are included in the plots to indicate where the difference between the two models is significant with a two-tailed paired Student's $t$ test with a $95 \%$ confidence interval.

When we compare the model runs, we compare the model version with and without an explicit treatment of the smallest particles. We therefore introduce the following subgroups of particle number concentration. We refer to particle number concentrations excluding particles in the sectional scheme as $N_{a}$. This includes all the particles for the OsloAero simula-

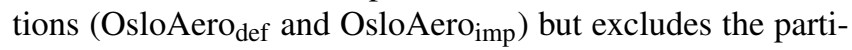
cles still in the sectional scheme for OsloAeroSec. Furthermore, the total number of aerosols we refer to as $N_{\text {tot }}$, and the concentration of aerosols in the sectional scheme will be referred to as $N_{\mathrm{sec}}$. Finally, the aerosol scheme also tracks the number of particles in the modal scheme originating from $\mathrm{NPF}$, and this we denote as $N_{\mathrm{NPF}}$. This is summed up in Table 3. Note that changes in $N_{\mathrm{NPF}}$ and $N_{a}$ in general follow the same patterns because we do not introduce changes to particles other than those from NPF.

\subsection{Processing of model output data prior to comparison with observations}

We compare the nudged model simulations for the years 2008 and 2009 to observed size distributions from the EUSAAR dataset from Asmi et al. (2011a). The dataset con- tains time series of hourly data for number concentrations of particles with diameters between 30 and $50 \mathrm{~nm}\left(N_{30-50}\right)$, 50 and $500 \mathrm{~nm}\left(N_{50-500}\right), 100$ and $500 \mathrm{~nm}\left(N_{100-500}\right)$, and finally 250 and $500 \mathrm{~nm}\left(N_{250-500}\right)$. In this study, we focus on the concentration of particles with diameters between 50 and $100 \mathrm{~nm}$, i.e. $N_{50-100}=N_{50-500}-N_{100-500}$. Throughout the simulation period, we output hourly mean values describing the modelled size distribution.

The model outputs a log-normal fitting to the size distribution in terms of parameters for 12 log-normal modes. In other words, the total size distribution is

$$
\frac{\mathrm{d} N}{\mathrm{~d}\left(d_{p}\right)}=\sum_{i}^{12} \frac{\mathrm{d} N_{i}}{\mathrm{~d}\left(d_{p}\right)}
$$

Each term $\frac{\mathrm{d} N_{i}}{\mathrm{~d}\left(d_{p}\right)}$ is furthermore defined in terms of output parameters from the modal number median diameter, $d_{\mathrm{m}, i}$, geometric standard deviation, $S_{i}$, and the number concentration in the mode, $N_{i}$ :

$$
\frac{\mathrm{d} N_{i}}{\mathrm{~d}\left(d_{p}\right)}=\frac{N_{i}}{d_{p} \log \left(S_{i}\right) \sqrt{2 \pi}} \exp \left(-\frac{\left(\log \left(d_{p}\right)-\log \left(d_{\mathrm{m}, i}\right)\right)^{2}}{2 \log \left(S_{i}\right)}\right) .
$$

For each mode, we can then calculate the number of particles in a size range from diameter $d_{1}$ to $d_{2}$ by

$N_{i, d_{1}-d_{2}}=N_{i}\left(d<d_{2}\right)-N_{i}\left(d<d_{1}\right)$,

where $N_{i}$ is the cumulative distribution function of the distribution in Eq. (21), and thus

$N_{i}(d<x)=\frac{1}{2}+\frac{1}{2} \operatorname{erf}\left[\frac{\log (x)-\log \left(d_{\mathrm{m}, i}\right)}{\sqrt{2} \log \left(S_{i}\right)}\right]$.

The total number concentration in a size range is thus $N_{d_{1}-d_{2}}=\sum_{i=1}^{12} N_{i, d_{1}-d_{2}}$. We calculate these variables for 
Table 3. Model variable definitions.

\begin{tabular}{ll}
\hline Variable name & Definition \\
\hline$N_{a}$ & Number of particles excluding those in the sectional scheme \\
$N_{\text {tot }}$ & Number of particles including those in the sectional scheme \\
$N_{\mathrm{sec}}$ & Number of particles in the sectional scheme \\
$N_{\mathrm{NPF}}$ & Number of particles from NPF excluding those in the sectional scheme \\
$N_{d_{1}-d_{2}}$ & Number of particles with diameter $d$ such that $d_{1} \leq d \leq d_{2}$ \\
$N_{d_{1}}$ & Number of particles with diameter $d$ such that $d_{1} \leq d$ \\
\hline
\end{tabular}

each hour and compute further statistics from the result. By using such a fine time resolution, we avoid a common imprecision arising when averaging the parameters of the size distribution, $r_{\mathrm{m}, i}$ and $S_{i}$, over a longer time period (i.e. monthly output).

Furthermore, for the comparison of size distributions, we calculate $\frac{\mathrm{d} N}{\mathrm{~d} \log \left(d_{p}\right)}=d_{p} \frac{\mathrm{d} N}{\mathrm{~d}\left(d_{p}\right)}$ for an array of diameters and compute further statistics from the hourly values.

\section{Results and discussion}

\subsection{Comparison to EUSAAR dataset}

In this comparison we focus on $N_{50-100}$ because particles smaller than $50 \mathrm{~nm}$ are unlikely to be relevant for $\mathrm{CCN}$ and particles above $100 \mathrm{~nm}$ are less effected by the changes to the NPF scheme (see e.g. the size distributions in Fig. 4).

Figures 2 and S4 in the Supplement show the distribution of the modelled minus the observed values for $N_{50-100}$ at hourly resolution and with all valid station data included.

From Fig. 2 we can see a clear improvement with OsloAeroSec compared to both OsloAero def and OsloAero $_{\text {imp. The improvement is most pronounced in }}$ summer, when OsloAero ${ }_{\text {def }}$ and OsloAero imp overestimate $N_{50-100}$, while it is also clear in autumn and spring. It is also encouraging that OsloAeroSec has a clear decrease in the times when the number concentration is highly overestimated, while there is not a similar increase in times when it is underestimated. Furthermore, we see that changes to nucleation parameterization and diurnal variation in oxidants in OsloAero imp reduce the bias compared to OsloAero def. In winter, NPF is low, so we see little difference between the different schemes. Figure S4 shows the same as Fig. 2 but for each individual station. OsloAeroSec (OsloAeroSec) shows improvement against OsloAero (OsloAero $_{\text {def }}$ and OsloAero $_{\text {imp }}$ ) in most stations during JJA, while sometimes underestimating $N_{50-100}$ in MAM (e.g. VHL, MPZ, HWL).

The annual variability of both models and observations is shown in Fig. 3, where the monthly median (solid line) and percentiles (16th to 84th) are plotted for each station. Again it is clear that OsloAeroSec in general reduces the high bias of OsloAero def $_{\text {and OsloAero }}$ imp, especially when the bias is very high (e.g. OBK, HPB, FKL, ZSF, CMN,
BEO). The exceptions that stand out are e.g. CBW, JRC, ZEP and KPO, where all versions of the model do rather poorly in both absolute numbers and in terms of representing the annual variability. This might indicate that aerosol or precursor emissions in the model are not accurate e.g. due to local sources that are unaccounted for in the model. For CBW, NPF should not be an important source of aerosols during winter and autumn (Mamali et al., 2018), so it is likely that other aerosols are responsible for the underestimation during these seasons. Dall'Osto et al. (2018) note a strong influence of local anthropogenic emissions at this station, which is likely not captured in the CMIP6 emissions. However, during summer, the model may well show an underestimation of production of particles from NPF, which becomes slightly worse with OsloAeroSec. According to Dall'Osto et al. (2018), NPF should be most frequent in JRC and KPO during spring, which the $N_{50-100}$ does not really reflect, probably due to other particles dominating the annual variability. Furthermore, at ZEP station, the concentrations are underestimated in all months except late autumn and winter. At this station the concentrations in the sectional scheme (see Figs. 4 and S12-S15 in the Supplement) reveal that there are relatively many particles forming at this location, but they do not survive to $50 \mathrm{~nm}$. All models perform badly here, with OsloAeroSec and OsloAeroimp performing slightly worse than OsloAero $_{\text {def. In PLA and }}$ WAL, the OsloAeroSec results in values that are too low, while OsloAero $_{\text {def }}$ and OsloAeroimp perform better. In station MHD, FKL, ZSF, CMN and BEO, the model overestimation of $N_{50-100}$ is reduced in OsloAeroSec but is still significantly too high.

The normalized root mean square error (NRMSE) is improved with OsloAeroSec for both $N_{50-100}$ and $N_{50-500}$, while it stays more or less the same for $N_{100-500}$. The NRMSE is shown in Fig. S5 in the Supplement and is calculated for each season and each model version using hourly resolution and all available data. The greatest improvement is seen in $N_{50-100}$ and in summer, followed by SON and MAM, while DJF is mostly unchanged. $N_{50-500}$ shows improvement in the same seasons, while there only small improvements in prediction skill for $N_{100-500}$. The lack of change in prediction skill for particles larger than $100 \mathrm{~nm}$ likely originates from the fact that in CAM6-Oslo, the NPF particles no not 

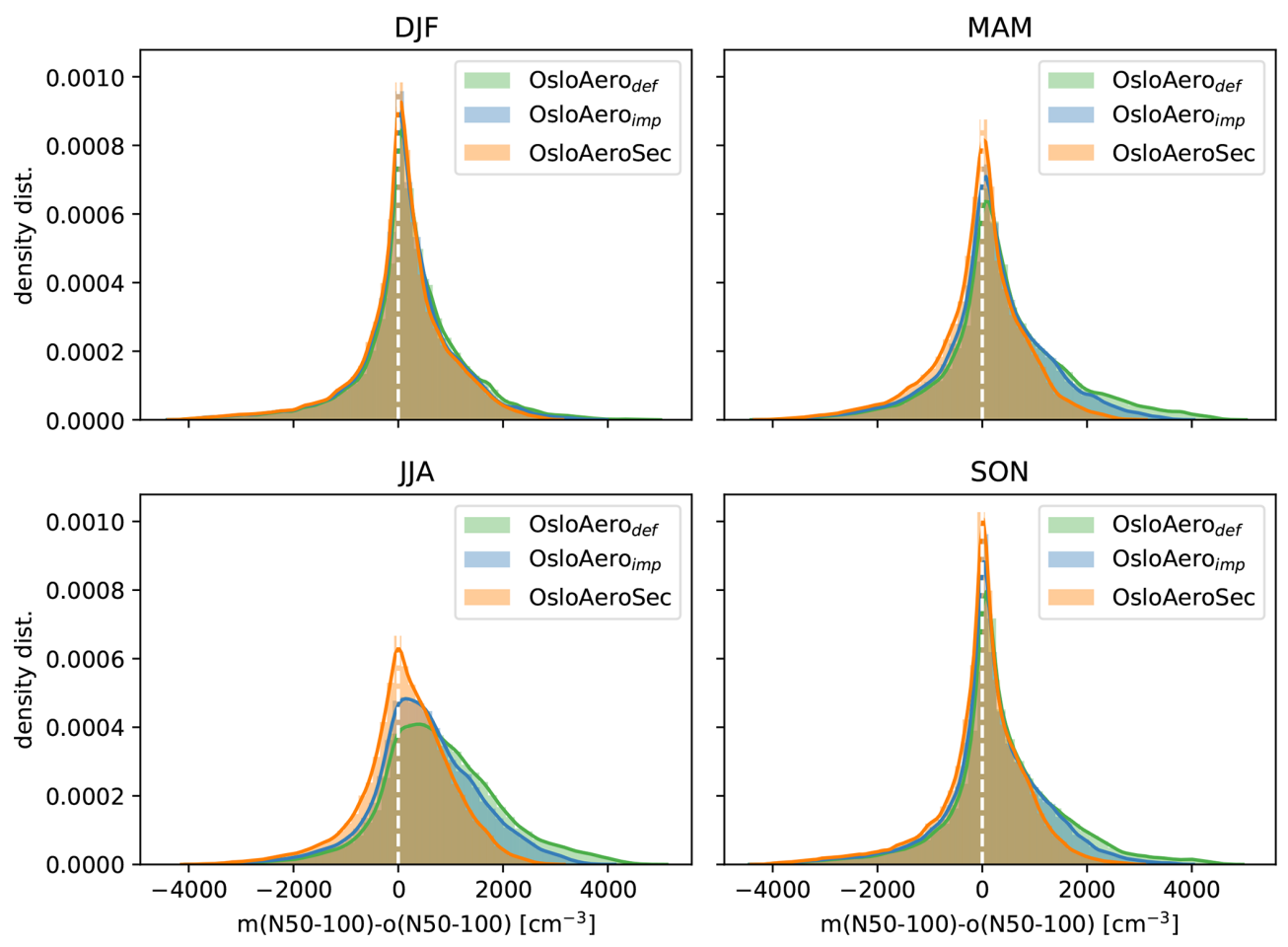

Figure 2. Seasonal distribution of modelled $N_{50-100}$ minus observed $N_{50-100}$ for all EUSAAR stations (Asmi et al., 2011a). We use hourly resolution, and all available station data are included.

change mode by condensational growth - rather, the whole mode grows in number median diameter. Thus, the variability in concentrations of particles larger than $100 \mathrm{~nm}$ is dominated by primary particle emissions, which we do not alter here.

Even though the $N_{50-100}$ improves, Fig. 4 reveals that the concentrations at smaller sizes are overestimated in most locations. The figure shows the size distribution of particles at each station from both observations and the three versions of CAM6-Nor. For the sectional scheme, the distribution is the sum of particles in the sectional scheme and the modal scheme. This is why it has "spikes" and why there is often a large reduction in $\mathrm{d} N / \mathrm{d}_{\log _{10}} D$ at the intersection between the sectional scheme and the modal scheme, which might be misunderstood to mean that disproportionately many particles are lost in the transition between the sectional and modal scheme. The distribution in the sectional scheme, without adding the modal particles, is shown by the dashed line. One important reason why the sectional scheme overestimated the number of the particles at the smallest sizes may be that the number of particles above $\sim 100 \mathrm{~nm}$ is underestimated in all the model versions in most of the stations (see e.g. the distribution of particle surface areas in Fig. S11 in the Supplement).

This is particularly pronounced in summer, when the number of particles in the sectional scheme is particularly high (see Fig. S13). Since NPF mostly influences nucleation and
Aitken-mode particles, this is likely due to other aerosol sources not being adequately represented in the model. This leads to an underestimation of coagulation sink and hence an overestimation of the formation rate. To the same effect, the condensation sink may be too low, again leading to too many new particles forming. This is particularly clear in the Arctic station Zeppelin (ZEP), where the measurements show a peak in particles between 100 and $200 \mathrm{~nm}$, which are completely missing in the models. The combination of an overly high formation rate and a slow condensation growth rate leads to too many particles in the smaller sizes.

Overall, adding the explicit treatment of the smaller particles in OsloAeroSec does improve the representation of $\mathrm{CCN}$ relevant particles in the model. We especially get a reduction in number concentrations of diameters above $50 \mathrm{~nm}$ at which they are significantly overestimated.

\subsection{Comparison to original model}

The following section will present general differences in OsloAeroSec compared to the two versions of the original model, OsloAero ${ }_{\mathrm{def}}$ and OsloAeroimp. For this analysis, we make use of the full global model output in monthly mean resolution. We will start by comparing the particle number concentrations and properties of the aerosols. The original version of the CAM6-Nor aerosol scheme does not explicitly model the smallest particles, so in order to get an applesto-apples comparison, we focus on properties relevant for 

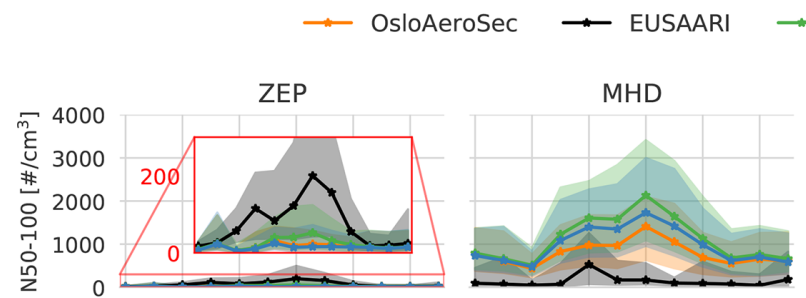

OsloAero $_{\text {def }}$

$\rightarrow$ OsloAero $_{i m p}$
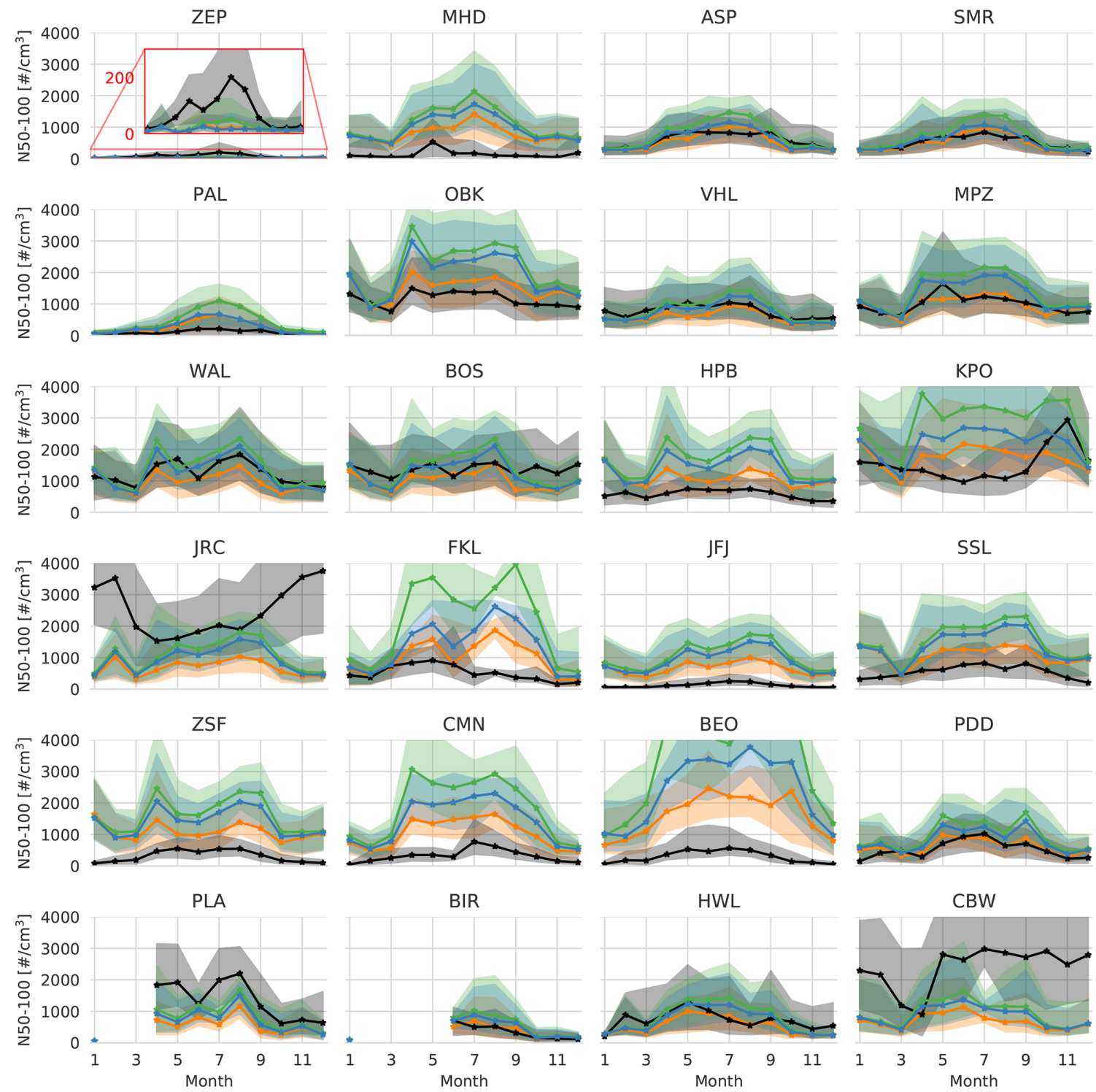

Figure 3. $N_{50-100}$ monthly median (solid line) and percentiles (shaded, 16th to 84th) for each station for each model version and the observed values (Asmi et al., 2011a). Stations where the full graph is not shown due to the axis limits are shown in full in Fig. S6 in the Supplement. Zeppelin (ZEP), Mace Head (MHD), Aspvreten (ASP), SMEAR II (SMR), Pallas (PAL), Kosetice (OBK), Vavihill (VHL), Melpitz (MPZ), Waldhof (WAL), Bösel (BOS), Hohenpeissenberg (HPB), K-Puszta (KPO), JRC-Ispra (JRC), Finokalia (FKL), Jungfraujoch (JFJ), Schauinsland (SSL), Zugspitze (ZSF), Monte Cimone (CMN), BEO Moussala (BEO), Puy de Dôme (PDD) Preila (PLA), Birkenes (BIR), Harwell (HWL), Cabauw (CBW).

climate, as represented by the modal aerosol scheme when comparing OsloAeroSec to OsloAero ${ }_{\text {def }}$ and OsloAeroimp. See Table 3 for a summary of the definitions of the variables defining number concentration. We then proceed to changes in cloud properties and finally the radiative effect.

\subsubsection{Aerosols}

The total number of particles, $N_{\text {tot }}$, increases in OsloAeroSec compared to OsloAero $_{\text {def }}$ and OsloAero $i m p$ due to the addition of particles not explicitly treated before. In Fig. 5 the absolute number of sectional particles, $N_{\mathrm{sec}}$, in OsloAeroSec is shown (a and c) together with the total number of particles, $N_{\text {tot }}$ (right, b and d). The maps in Fig. 5a and b show near-surface averages, as defined in Sect. 3.2. As can be 


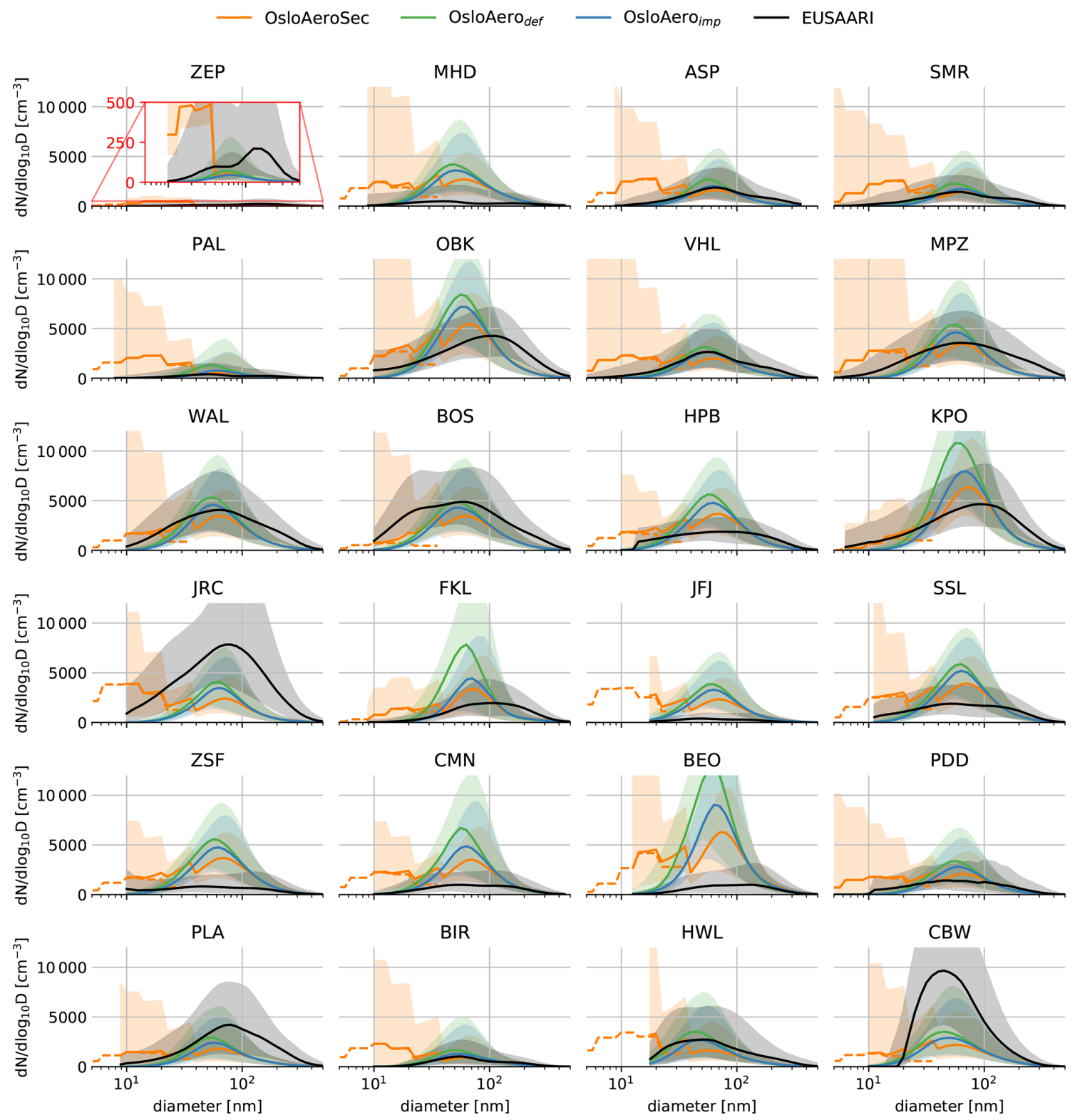

Figure 4. Median (solid line) particle number size distribution and shading from the 16th to 84th percentiles for observations (Asmi et al., 2011a) and models. All data when and where observations are available are included.

seen from Fig. 5d, the change is particularly strong in the upper troposphere, where $N_{\text {tot }}$ is very low in OsloAeroimp and OsloAero $o_{\text {def }}$ because the smallest particles are simply not represented in these model versions.

Figure 6a shows averaged profiles of $N_{a}$ for each model version, while Fig. $6 \mathrm{~b}$ and $\mathrm{c}$ show maps of the near-surface relative difference in OsloAeroSec compared to OsloAero def and OsloAero ${ }_{i m p}$, respectively. On average, the global nearsurface $N_{a}$ decreases in OsloAeroSec by $15 \%$ compared to OsloAero $_{\text {imp }}$ and $36.2 \%$ compared to OsloAero ${ }_{\text {def }}$. However, at high latitudes the change relative to OsloAero imp is small, or positive, especially over the Southern Ocean. When considering the vertical change shown in Fig. 6a, OsloAeroSec has fewer particles close to the surface, while the difference is reduced further up in the atmosphere. In the free troposphere, i.e. further away from the surface, the difference becomes positive and OsloAeroSec lets more particles survive through early growth. For the global average this happens roughly at $700 \mathrm{hPa}$, while over ocean it happens at $800 \mathrm{hPa}$. Over the continents, OsloAeroimp is always higher, though the difference decreases with height. From these results, we can conclude that on average the sectional scheme produces more particles in more remote regions both horizontally and vertically.

In all model versions, the growth of the particles from nucleation to the smallest mode happens by condensa- 
(a) OsloAeroSec, $\mu=1199.5 \mathrm{~cm}^{-3}$

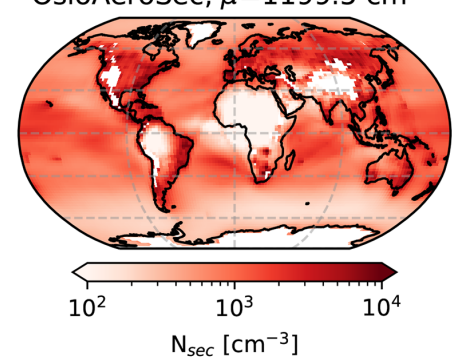

(c)

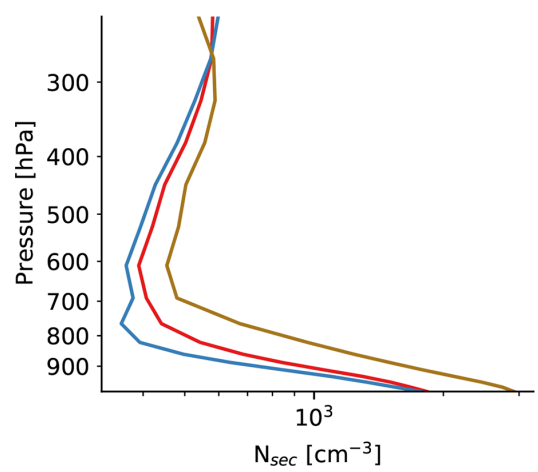

(b) OsloAeroSec, $\mu=1916.7 \mathrm{~cm}^{-3}$

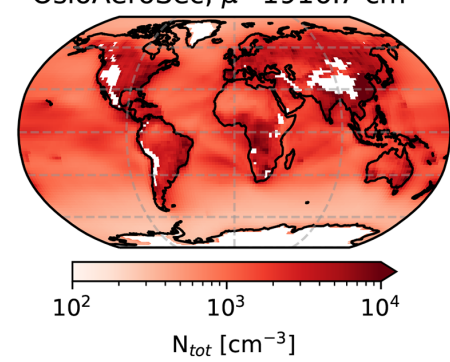

(d)

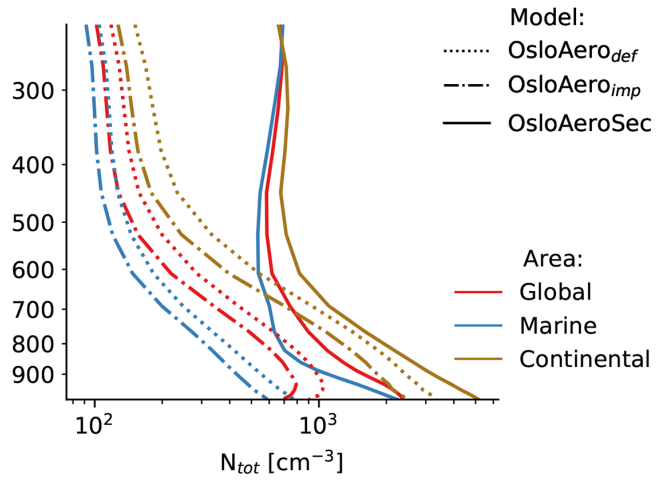

Figure 5. Modelled particle number concentrations. Panels (a) and (b) show maps of the near-surface average concentrations for $N_{\text {sec }}$ (a) and $N_{\text {tot }}$ (b) in OsloAeroSec. Panels (c) and (d) show average profiles globally, over continents (continental) and over ocean (marine) for $N_{\text {sec }}$ (c) and $N_{\text {tot }}(\mathbf{d})$. In (d), OsloAero def $_{\text {and OsloAero }}$ imp are also included.
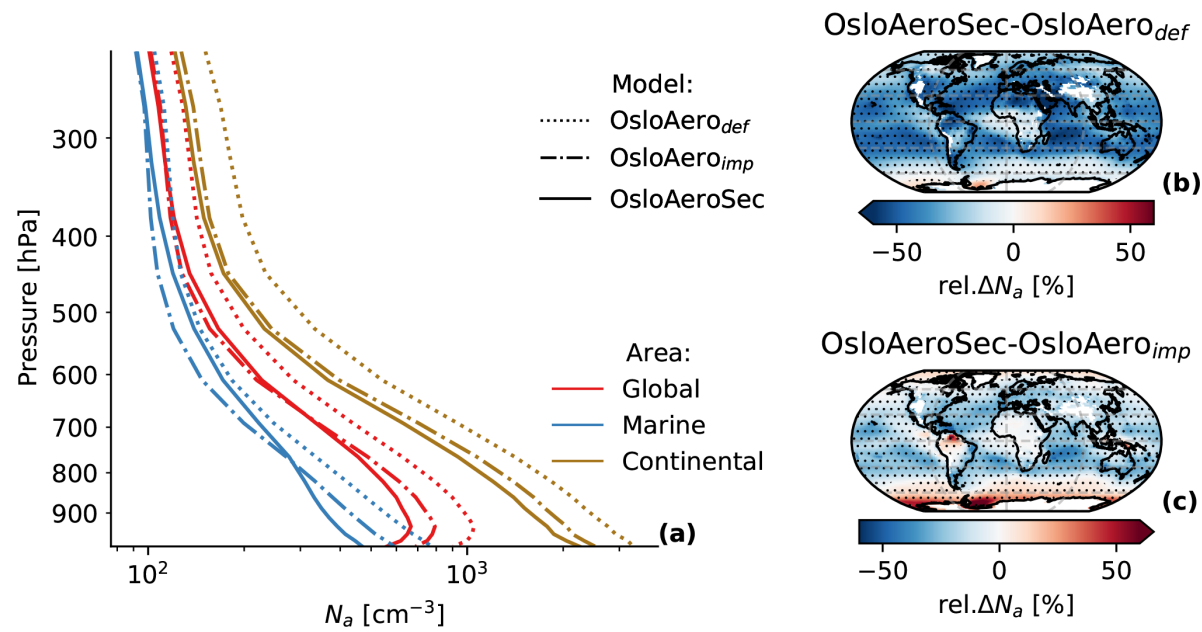

Figure 6. Comparison of $N_{a}$ from OsloAero def $_{\text {and OsloAero }}$ imp to OsloAeroSec. (a) Profiles of the mean of regions (global, marine and continental) for the model versions. (b, c) The relative difference in the near-surface mean of OsloAeroSec compared to OsloAero def and OsloAero $_{i m p}$, respectively. Areas where the difference is significant $(95 \%)$ are marked with dots.

tion of the two tracers $\mathrm{H}_{2} \mathrm{SO}_{4}$ and $\mathrm{SOAG}_{\mathrm{LV}}$. The relative contribution of $\mathrm{H}_{2} \mathrm{SO}_{4}$ and $\mathrm{SOAG}_{\mathrm{LV}}$ to this growth changes with OsloAeroSec but, interestingly, also between OsloAero $_{\text {def }}$ and OsloAero $i m p$. Figure 7 a shows the secondary organic aerosol (SOA) fraction of the particles that have survived to the modal scheme averaged over regions. Firstly, the SOA fraction goes down in OsloAeroimp com- pared to OsloAero ${ }_{\text {def }}$, and secondly, globally it goes up with OsloAeroSec. We start by exploring the difference between OsloAero def and OsloAeroimp. These two simulations have the same parameterization for survival of particles from nucleation up to the model scheme (see Sect. 2.2), but OsloAero ${ }_{i m p}$ has an improved diurnal variation in the oxidants, resulting in a higher diurnal peak in $\mathrm{H}_{2} \mathrm{SO}_{4}$ (not 

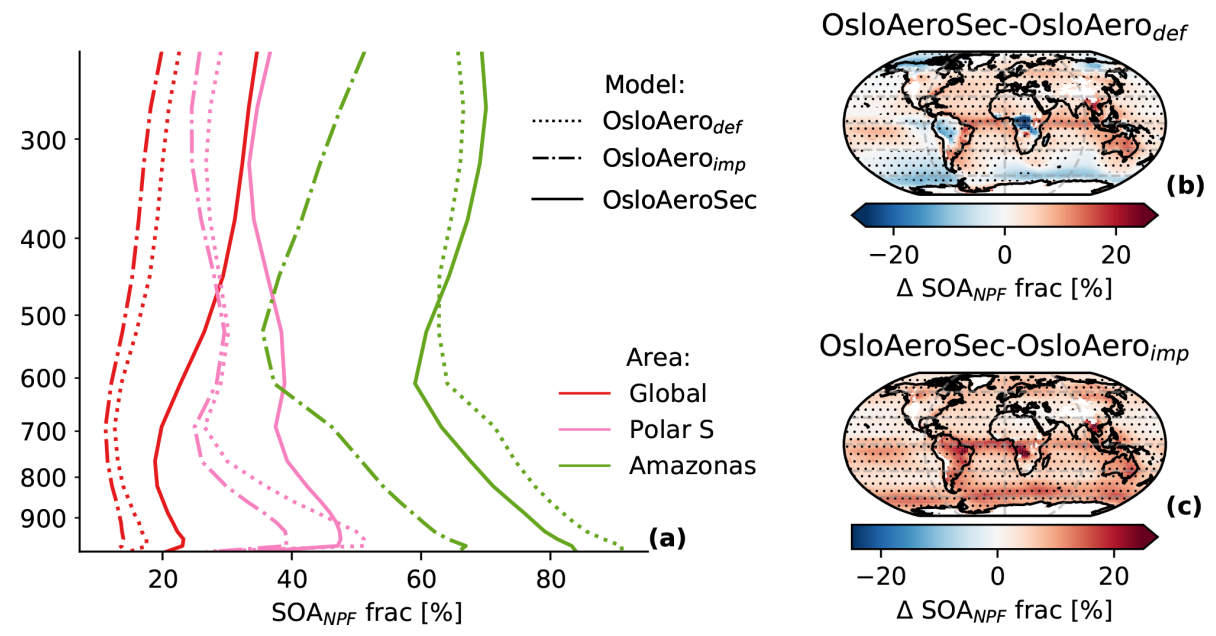

Figure 7. The SOA fraction of $N_{\mathrm{NPF}}$ mass $\left(\mathrm{SOA}_{\mathrm{NPF}}\right)$, i.e. the fraction of the growth of the particles before they reach the modal scheme, which is due to organics. (a) Profiles for regions (global, polar south, Amazonas) with each model. (b, c) The difference in the near-surface mean values for OsloAeroSec minus OsloAero def and OsloAero $_{i m p}(\mathbf{c})$, respectively. Areas where the difference is significant $(95 \%)$ are marked with dots.

shown). Additionally, the nucleation parameterization in OsloAero ${ }_{\text {imp }}$ is of the form $\mathrm{H}_{2} \mathrm{SO}_{4}{ }^{2} \times$ ELVOC, meaning that as $\mathrm{H}_{2} \mathrm{SO}_{4}$ increases, the nucleation rate increases to the

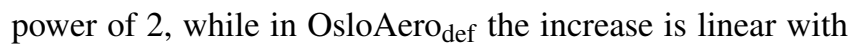
both $\mathrm{H}_{2} \mathrm{SO}_{4}$ and ELVOC. Furthermore, because the growth from the nucleation to modal scheme happens within one time step in these simulations, the fraction of growth from SOA is entirely based on $\mathrm{H}_{2} \mathrm{SO}_{4}$ and ELVOC at the moment of nucleation. This means that if most of the particles form when $\mathrm{H}_{2} \mathrm{SO}_{4}$ is at its highest, $\mathrm{H}_{2} \mathrm{SO}_{4}$ will also dominate the post-nucleation growth. This explains the reduced contribution of SOA in OsloAeroimp relative to OsloAero ${ }_{\text {def. }}$.

The change seen in OsloAeroSec compared to OsloAero $_{\text {def }}$ and OsloAeroimp, on the other hand, can be explained by two factors: (1) though OsloAeroSec has the same changes to oxidants and nucleation parameterization as

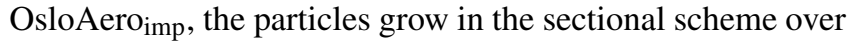
more than one time step and are thus exposed to different concentrations of $\mathrm{H}_{2} \mathrm{SO}_{4}$ and $\mathrm{SOAG}_{\mathrm{LV}}$. Thus, the concentrations at the time of nucleation will be less dominant for the

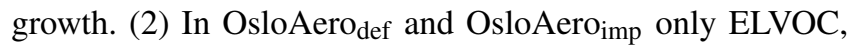
which is $50 \%$ of the $\mathrm{SOAG}_{\mathrm{LV}}$, will contribute to growing the particles up to the modal scheme, while in OsloAeroSec $100 \%$ of the $\mathrm{SOAG}_{\mathrm{LV}}$ can contribute after the particles have reached the sectional scheme $(5 \mathrm{~nm})$, thus increasing the SOA fraction. The result is a combination of these effects; in some regions, like over the Amazon, the effect seems to be dominated by the change in nucleation timing such that the

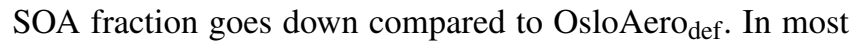
regions the effect is that the SOA fraction increases.

Note that the changes in hygroscopicity from this are minor and mitigated by the fact that additional condensate is added to the particles after they reach the modal scheme.
The strength and sign of the change in number concentration between OsloAeroSec and the original model vary with location.

To investigate what conditions lead to the changes in NPF particles, we focus on the difference in $N_{\mathrm{NPF}}$ between OsloAeroSec and OsloAeroimp and analyse its relationship to relevant variables in OsloAero $i m p$. Thus, we can analyse under which conditions in the model (polluted, clean, high NPF etc.) $N_{\mathrm{NPF}}$ increases or decreases with the sectional scheme. Figure 8 shows the relationship for nucleation rate ( $J_{\text {nuc }}$, a), growth rate $(\mathrm{GR}, \mathrm{b}), \mathrm{H}_{2} \mathrm{SO}_{4}(\mathrm{c}), \mathrm{SOAG}_{\mathrm{LV}}(\mathrm{d}), N_{\mathrm{NPF}}$ (e) and coagulation sink for newly formed particles (CoagS, f). This 2D histogram includes each grid cell below $100 \mathrm{hPa}$, and monthly mean values are used for each grid cell.

Firstly, most of the variables show a branch with a strong negative relationship with the change in $N_{\mathrm{NPF}}\left(\Delta N_{\mathrm{NPF}}\right)$. Further investigation shows that the grid cells that constitute this branch are mainly close to the surface and, as can be seen from Fig. 8e, where $N_{\text {NPF }}$ and CoagS are high. In other words, what we are seeing is that in regions with high CoagS and $N_{\mathrm{NPF}}$, the sectional scheme drastically reduces the number of particles that survive and reduces it more the higher

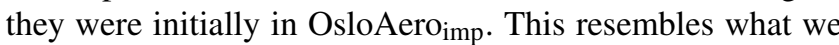
saw when comparing to station data, with the very high overestimations particularly reduced.

For the other grid cells, in which $N_{\mathrm{NPF}}$ and CoagS are lower, there is another branch showing a positive relationship with $\mathrm{GR}, \mathrm{H}_{2} \mathrm{SO}_{4}$ and $\mathrm{SOAG}_{\mathrm{LV}}$. From panels (e) and (f), it is clear that these grid cells have $N_{\mathrm{NPF}}$ concentrations under roughly $100 \mathrm{~cm}^{-3}$ and CoagS under roughly $10^{-3} \mathrm{~h}^{-1}$. In this regime the sectional scheme allows more particles to survive, and condensational growth is more important. 


$$
\begin{gathered}
\mathrm{N}_{N P F}\left(m_{1}\right)-\mathrm{N}_{N P F}\left(m_{2}\right) \text { vs. } X\left(m_{2}\right) \\
\text { for } m_{1}=\text { OsloAeroSec, } m_{2}=\text { OsloAero } i m p
\end{gathered}
$$

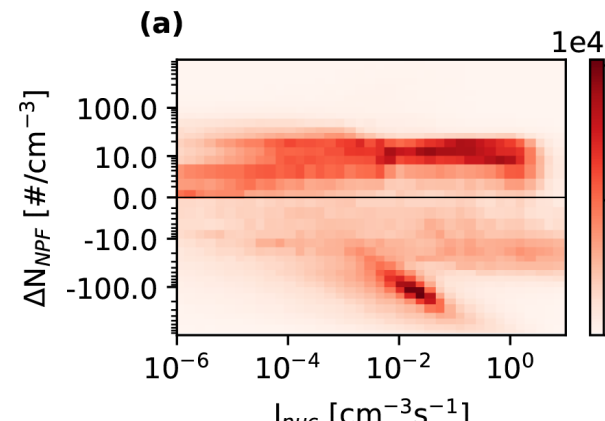

(b)
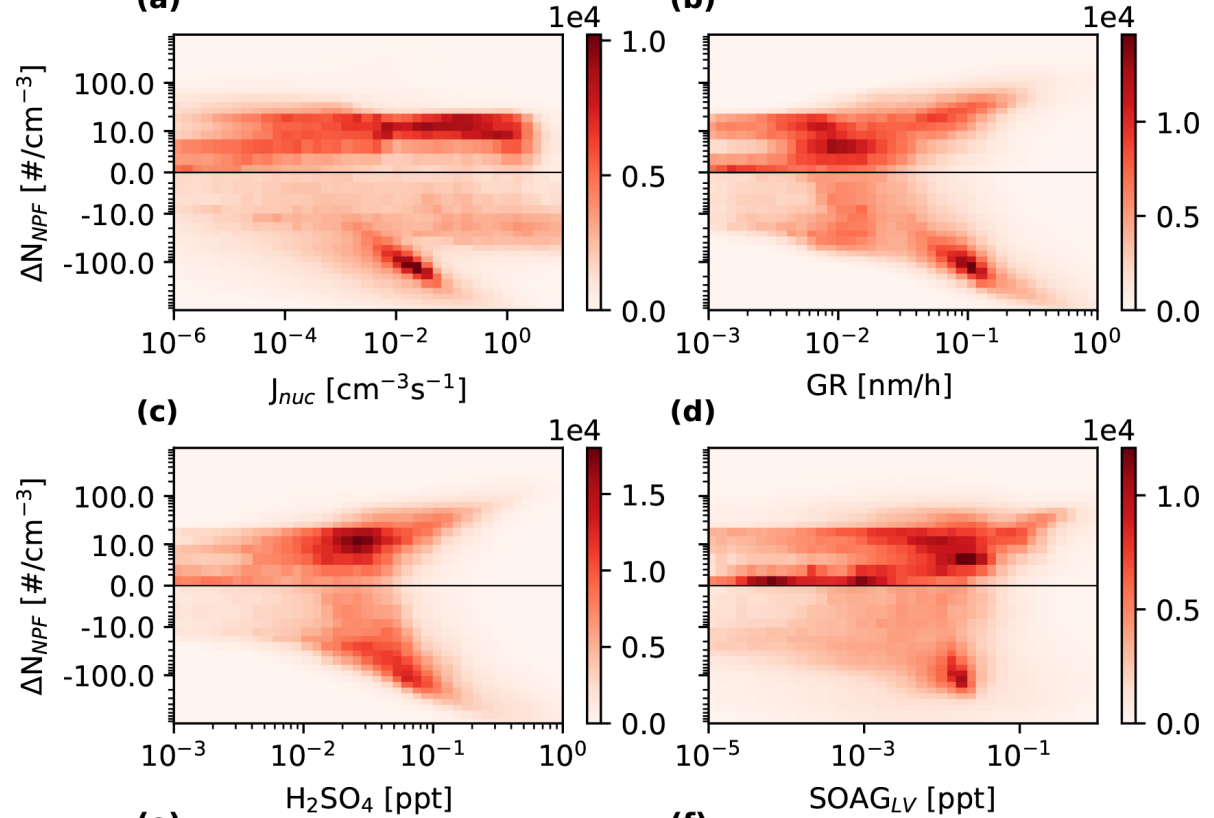

(d)
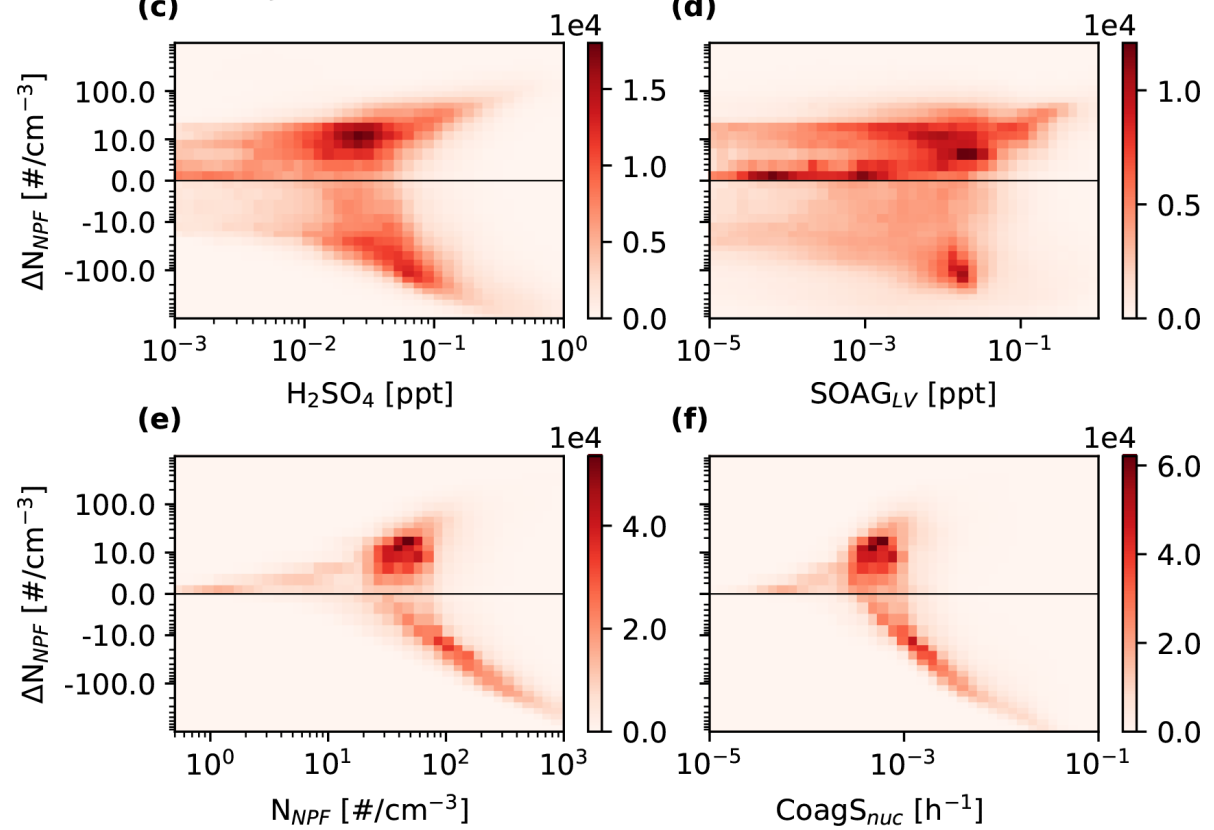

Figure 8. Two-dimensional histogram of the relation between various factors in the original model run OsloAero imp $_{\text {and }}$ the change in the

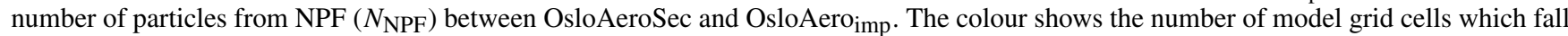
within the $x-y$ range using monthly mean files. Only grid cells below $100 \mathrm{hPa}$ are included. The values on the $x$ scale are the nucleation rate (a), the growth rate of newly formed particles (b), the mixing ratio of $\mathrm{H}_{2} \mathrm{SO}_{4}$ (c), the mixing ratio of $\mathrm{SOAG}_{\mathrm{LV}}(\mathbf{d})$, the concentration of particles from NPF (e) and the coagulation sink for newly formed particles (f). See Fig. S17 in the Supplement for the same plot, but with $N_{\mathrm{NPF}}$ from OsloAero ${ }_{\text {imp }}$, i.e. not the change.

In sum this means that in regions with very high number concentrations initially, the sectional scheme reduces the number of particles that survive proportional to the coagulation sink and the initial number of particles, while when the number of particles is initially small, the sectional scheme lets more particles survive and the change is more proportional to the concentration of condensing vapours.

As mentioned before, the Lehtinen et al. (2007) parameterization assumes steady-state GR and CoagS throughout the growth up to the aerosol model cut-off diameter, while in reality aerosol often forms e.g. when the GR is high and the CoagS is relatively low. The steady-state assumption is likely to give especially biased results in areas with high variability in aerosol and precursor concentrations. Since this is especially the case in areas with a high aerosol concentration, like the boundary layer, this may be why it is especially here that the sectional scheme reduces $N_{\mathrm{NPF}}$. In the sectional scheme, the particles may grow over some time and space before reaching the modal scheme and thus experience other concentrations.

\subsubsection{Cloud-aerosol interactions}

The sectional scheme affects the $\mathrm{CCN}$ concentrations by influencing the number of particles that survive to the modal scheme and thus also influences the cloud droplet activation scheme. The changes to cloud properties are shown in Figs. 9e- $\mathrm{h}$ and 10. We include variables that indicate changes 
to cloud properties from cloud-aerosol interaction. Unfortunately, CCN calculations are not currently available for CAM6-Nor.

We start by discussing the changes in OsloAeroSec compared to OsloAeroimp shown in the right column of Figs. 9 and 10. Figure $9 \mathrm{f}$ and $\mathrm{h}$ show the change between OsloAeroSec and OsloAero imp in cloud droplet number concentration (CDNC) and $r_{\mathrm{e}}$ averaged over longitude and time. These plots reveal that the CDNC increases and $r_{\mathrm{e}}$ decreases at most latitudes and heights, except above $\sim 40^{\circ} \mathrm{N}$.

Considering the change in $N_{\mathrm{NPF}}$ shown in Fig. 9b, the change in cloud properties reveals a highly non-linear response in Fig. 9f; the CDNC increases (and similarly $r_{\mathrm{e}}$ decreases) both where there are more NPF particles $\left(N_{\mathrm{NPF}}\right)$ (high in the Southern Hemisphere atmosphere) and where there are fewer (near the surface in the tropics). To investigate this, we show in Fig. 11a and b the Pearson correlation coefficient between $\Delta N_{\mathrm{NPF}}$ and $\Delta \mathrm{CDNC}$ calculated for each latitude and pressure level along time (monthly mean) and longitude. The pattern shows that in remote regions, i.e. polar and high troposphere, higher $N_{\mathrm{NPF}}$ is positively correlated with higher CDNC, while in less remote regions, the opposite is the case. The correlations are very similar when comparing to OsloAero ${ }_{\text {def }}$ (Fig. 11a) and OsloAero imp (Fig. 11b). These regions correspond roughly to regions of low particle concentrations (upper atmosphere) and high particle concentrations (surface). The reason for these correlations is likely that when the number of particles decreases, the amount of condensate available for each particle increases, thus increasing the number median diameter of each mode. This is seen in Fig. 9b and d, where we have inverse patterns in the difference in $N_{\mathrm{NPF}}$ and number median radius for NPF particles $\left(\mathrm{NMR}_{\mathrm{NPF}}\right)$. Since decreasing the number of particles in general causes the remaining particles to be larger, there may be fewer particles in total, but a larger fraction of the ones that are left is likely to activate. In polluted regions, there are many particles which compete for the same water vapour independently of which NPF scheme is used. The maximum supersaturation will therefore be lower, and the minimum activation diameter will be higher, than in remote regions, assuming all else to be equal. Therefore, the NPF particles may be less likely to activate in polluted regions anyway, and the change in size of the larger particles with NPF will be what governs the change in CDNC.

In more remote regions, the maximum supersaturation will be higher and the activation diameter smaller. Thus, the NPF particles will be more likely to activate directly, and changes to CDNC will be governed by changes in the absolute number of particles rather than the change in the size of the particles.

Keeping this in mind, the cloud property changes are easier to explain. When the number concentration decreases in remote regions, the $\mathrm{CDNC}\left(r_{\mathrm{e}}\right)$ increases (decreases) and the opposite for non-remote regions.
In general these results are reflected in Fig. 10, showing the changes in cloud properties on maps. There are significant differences over large parts of the high-latitude regions and the Amazon: an increase in column-integrated cloud droplet number ( $\left.\operatorname{col}_{\text {droplets, }}, \mathrm{b}\right)$, a decrease in cloud-top effective droplet radius $\left(r_{\mathrm{e}}(\mathrm{CT}), \mathrm{d}\right)$ and an increase in total cloud water path (CWP, f). Note that there is a reverse pattern over the continental Northern Hemisphere, where coldroplets decreases, $r_{\mathrm{e}}(\mathrm{CT})$ increases and CWP decreases.

The difference in $N_{\mathrm{NPF}}$ between OsloAeroSec and OsloAero $_{\text {def }}$ in Fig. 9a shows a stronger and more prevalent decrease than the difference between OsloAeroSec and OsloAero $_{\text {imp }}$ in Fig. $9 \mathrm{~b}$ due to the fact that OsloAero ${ }_{\text {def }}$ has, in general, more particles than OsloAeroimp.

The cloud effects closely follow the same rationale as for OsloAeroSec vs. OsloAeroimp, explained above: the decrease in polluted regions (tropics, close to the surface) brings an increase in CDNC, while a decrease in remote regions (Northern Hemisphere, free troposphere) brings a decrease in CDNC.

The right column in Fig. 10 shows maps for the relative difference between OsloAeroSec and OsloAero $_{\text {def. }}$ In this case the hemispheric asymmetry is clearer than for OsloAeroSec vs. OsloAeroimp: in the Northern Hemisphere above $\sim 30^{\circ}$, we have a decrease in col droplets $_{\text {(a), }} r_{\mathrm{e}}$ clearly increases (c), CWP decreases (e) and the net cloud effect is a slight warming $(\mathrm{g})$. Over the South Pole and large parts of the tropics, the opposite is the case.

The result is that the cloud effects of particles from NPF may depend highly on where these are formed.

\subsubsection{Radiative effects}

The changes in cloud properties discussed in the section above entail changes to the net cloud radiative effect (NCRE), shown in Fig. 10g and d. The globally averaged NCRE becomes more negative with OsloAeroSec compared to both OsloAero def $\left(-0.05 \mathrm{~W} \mathrm{~m}^{-2}\right)$ and OsloAero $i m p$ $\left(-0.11 \mathrm{~W} \mathrm{~m}^{-2}\right)$. The globally averaged $\triangle \mathrm{NCRE}$ is less negative for OsloAeroSec-OsloAero def because there are quite strong compensating positive values in the northern middle to high latitudes.

Aerosols can scatter or absorb radiation directly, and this effect is referred to as the direct aerosol effect. OsloAeroSec can affect the climate not only through changes in the cloud radiative effect, but also to a lesser extent through changes in the direct aerosol effect. We calculate the direct aerosol effect with the method of Ghan (2013). The change in direct aerosol radiative effect (DRE) is shown in Fig. 12. In general the change is small, with up to $\pm \sim 0.4 \mathrm{~W} \mathrm{~m}^{-2}$ regionally and 0.03 and $0.02 \mathrm{~W} \mathrm{~m}^{-2}$ globally, compared to OsloAero def and OsloAero ${ }_{\text {imp }}$, respectively. This is because the influence of the sectional scheme on the particles large enough to interact directly with radiation is rather small. What we do see is likely due to the fact that when number concentrations de- 

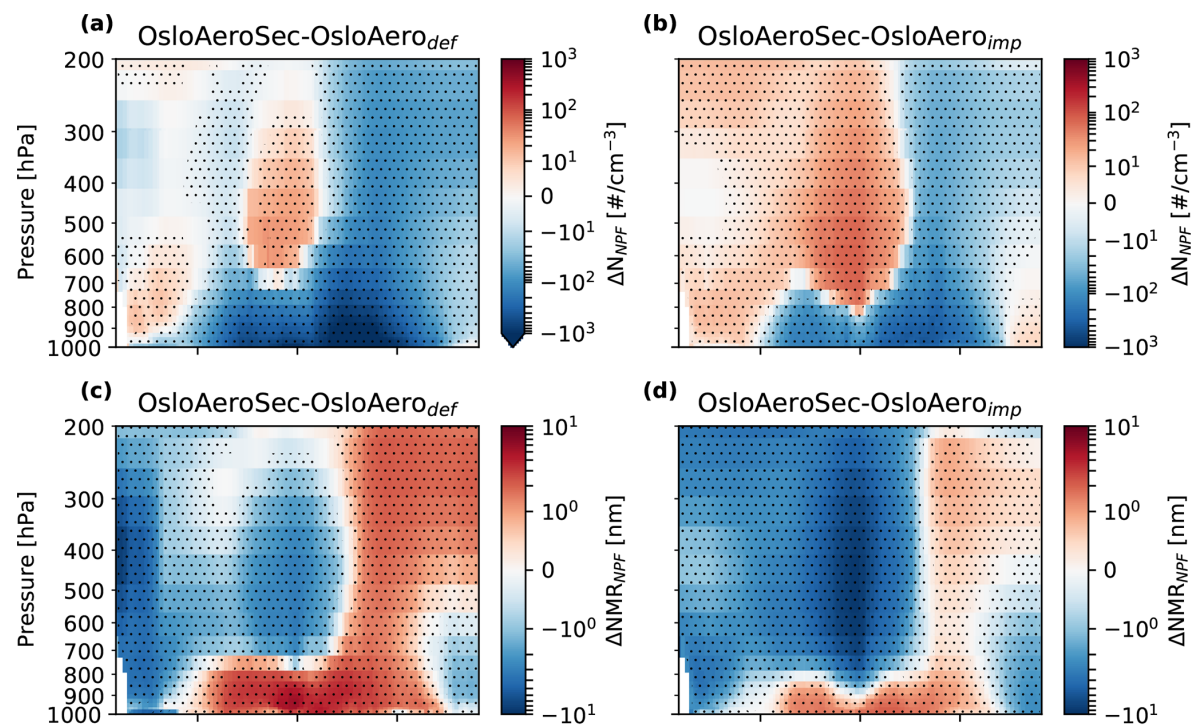

(d) OsloAeroSec-OsloAero $i m p$
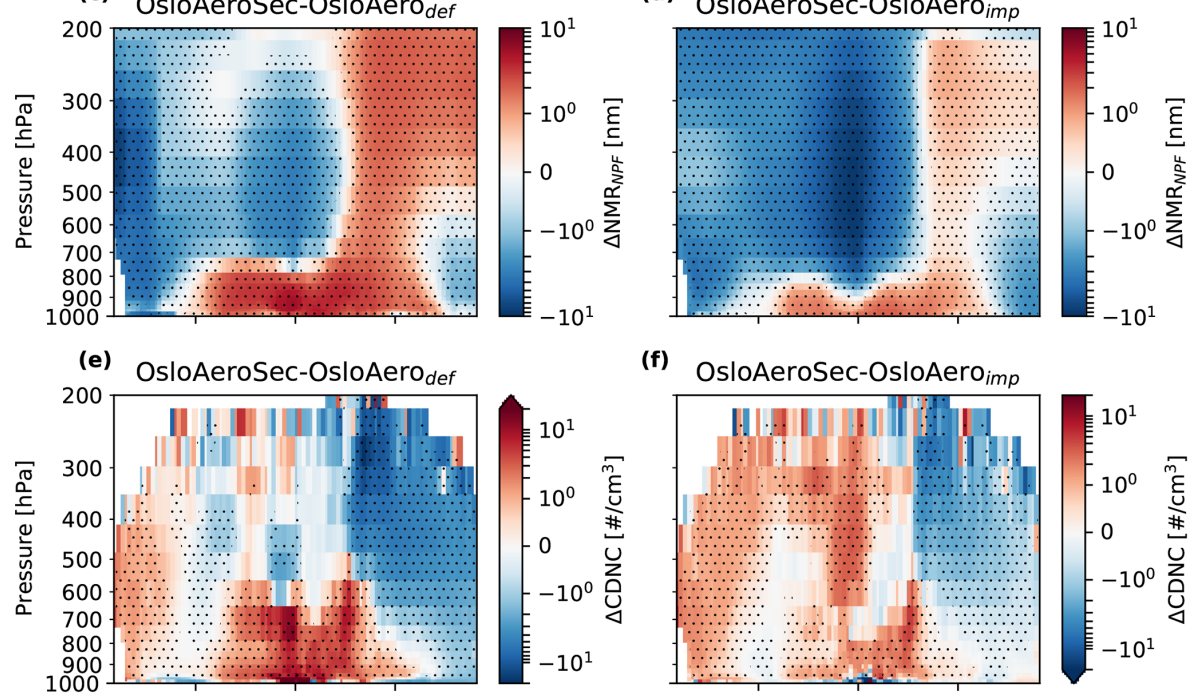

(f)
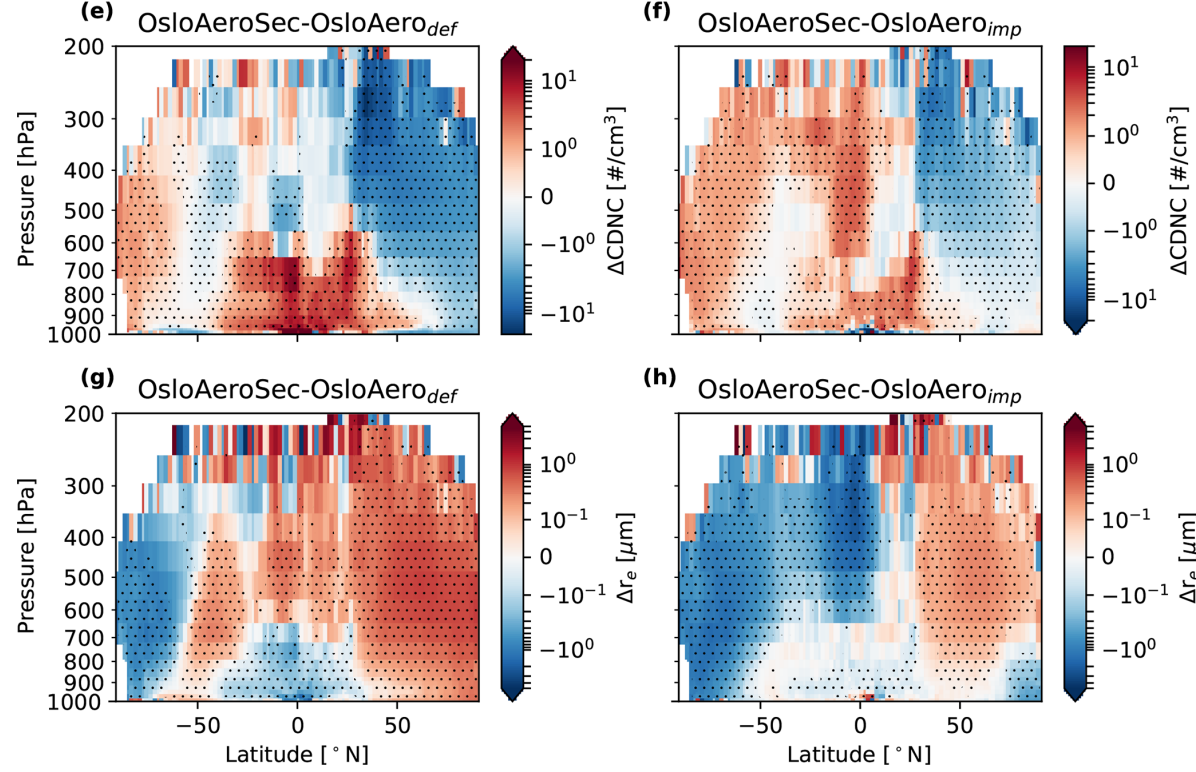

(h) OsloAeroSec-OsloAero ${ }_{\text {imp }}$

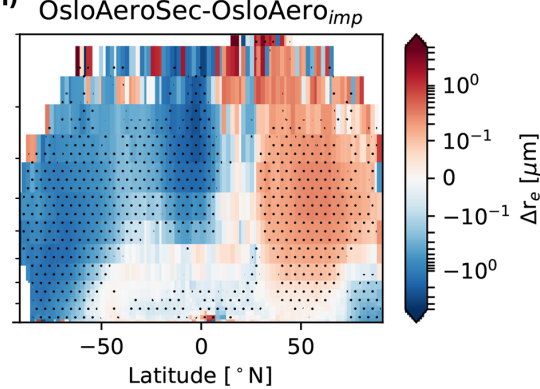

Figure 9. Zonally averaged change between OsloAeroSec and OsloAero ${ }_{\text {def }}(\mathbf{a}, \mathbf{c}, \mathbf{e}, \mathbf{g})$ and between OsloAeroSec and OsloAero $i m p$ (b, $\left.\mathbf{d}, \mathbf{f}, \mathbf{h}\right)$ in $N_{\mathrm{NPF}}(\mathbf{a}$ and $\mathbf{b})$, the number median radius for NPF particles $\left(\mathrm{NMR}_{\mathrm{NPF}}, \mathbf{c}\right.$ and $\left.\mathbf{d}\right)$, cloud droplet number concentration $(\mathrm{CDNC}, \mathbf{e}$ and $\mathbf{f})$ and cloud droplet effective radius $\left(r_{\mathrm{e}}, \mathbf{g}\right.$ and $\left.\mathbf{h}\right)$. Areas where the difference is significant $(95 \%)$ are marked with dots.

crease (increase), we get an increase (decrease) in condensate available for each particle. Thus, more (fewer) particles grow into the range in which they can interact directly with radiation. This is illustrated by the top two rows in Fig. 9, showing the $N_{\mathrm{NPF}}$ and number median radius of the NPF particles which have inverse patterns, as was also seen in Sporre et al. (2020).

\subsection{Sensitivities to sectional scheme assumptions}

To investigate how sensitive the scheme is to the setup, we performed several sensitivity tests whereby we varied both the number of bins in the scheme and the time step. These are presented in Sect. 1 in the Supplement. The sensitivity to the time step is low and changes the number of particles originating from NPF by less than $2 \%$. The sensitivity to the number of bins is slightly higher, with a $7 \%-8 \%$ increase in NPF particles when the number of bins is increased from five to eight, indicating that numerical diffusion plays some role. Reducing the number of bins to three decreases the NPF particle concentration by approximately $12 \%$, indicating that reducing the number of bins is unwise. These tests also indicate the strength of the numerical diffusion because it is known to decrease with increasing resolution in the bins. These tests indicate that numerical diffusion does play some role. On the other hand, increasing the number of bins from 
(a)

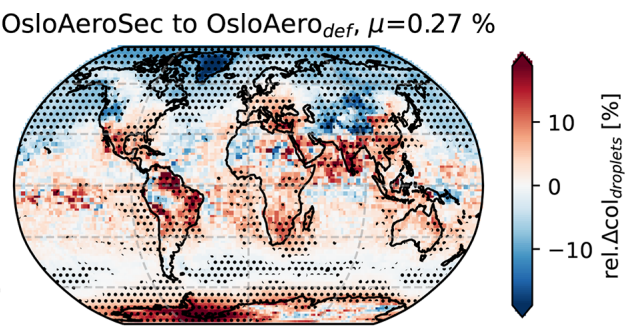

(c)

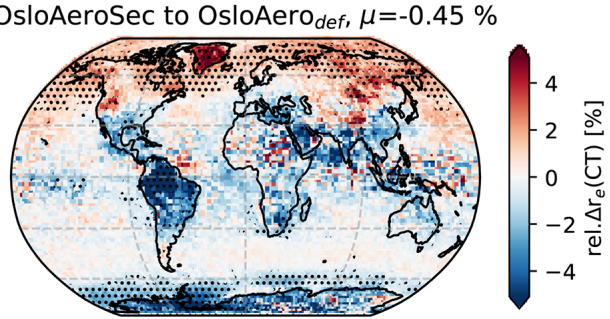

(e)

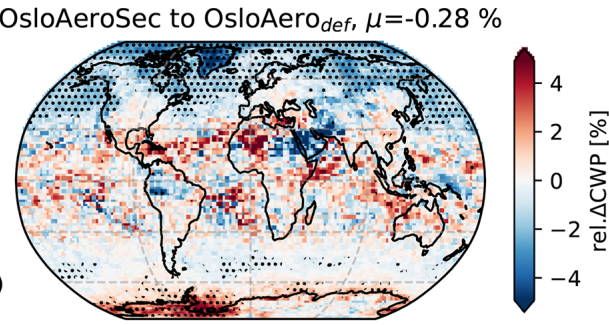

OsloAeroSec-OsloAero $_{\text {def }}, \mu=-0.05 \mathrm{~W} / \mathrm{m}^{2}$

(g)

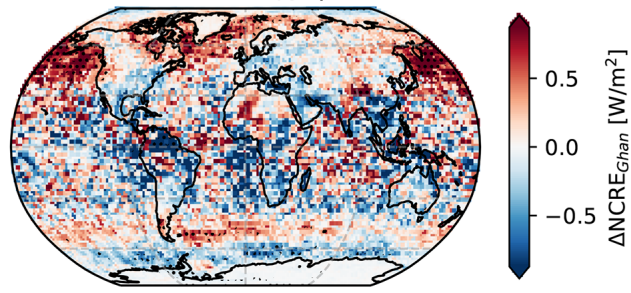

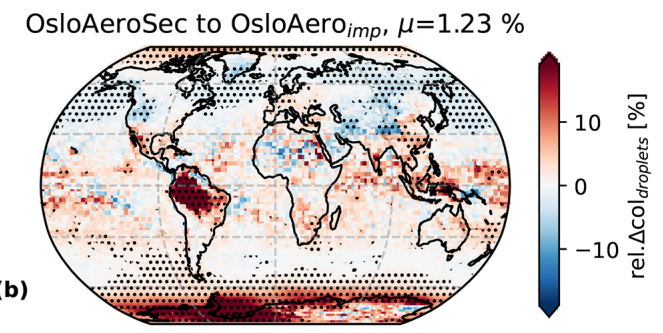

OsloAeroSec to OsloAero ${ }_{i m p}, \mu=-0.60 \%$

(d)

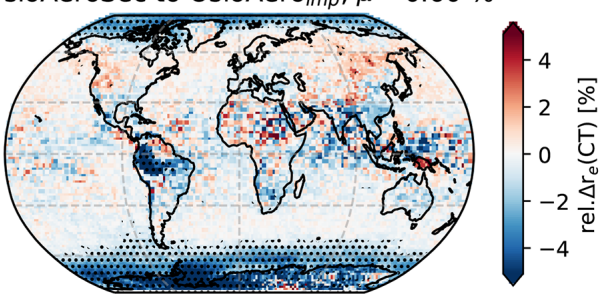

OsloAeroSec to OsloAero $_{i m p}, \mu=0.21 \%$

(f)

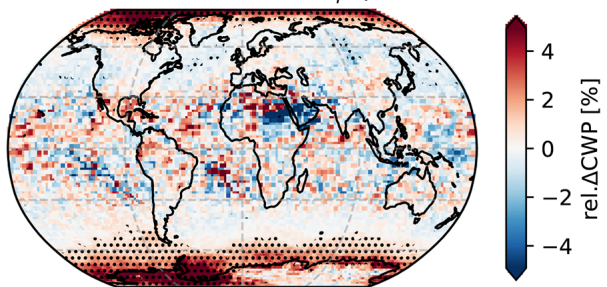

(h)

OsloAeroSec-OsloAero ${ }_{i m p}, \mu=-0.11 \mathrm{~W} / \mathrm{m}^{2}$

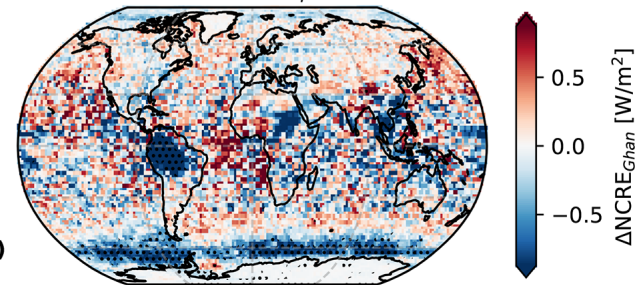

Figure 10. Changes to cloud properties. Panels $(\mathbf{a}, \mathbf{c}, \mathbf{e}, \mathbf{g})$ show the difference between OsloAeroSec and OsloAero $\mathrm{def}$ and panels $(\mathbf{b}, \mathbf{d}, \mathbf{f}, \mathbf{h})$ show the difference between OsloAeroSec and OsloAero imp. Panels (a) and (b) show the relative difference in cloud-top droplet number concentration $(\mathrm{CDNC}(\mathrm{CT}))$, panels $(\mathbf{c})$ and $(\mathbf{d})$ show the relative difference in effective droplet radius at cloud top $\left(r_{\mathrm{r}}(\mathrm{CT})\right)$, panels $(\mathbf{e})$ and (f) show the relative difference in cloud water path (CWP), and finally panels (g) and (h) show the difference in net cloud radiative effect (NCRE) calculated as recommended in Ghan (2013). Areas where the difference is significant (95\%) are marked with dots.

five to eight results in a $15 \%$ increase in computational cost, illustrating the need to balance accuracy and keeping computational costs low in ESMs.

\section{Implications and further discussion}

From the results above, it is clear that including explicit treatment of the early growth in OsloAeroSec does increase prediction skill compared to the original parameterization for particles above $50 \mathrm{~nm}$ in diameter. The difference is largest in summer, when the sectional scheme reduces the number of particles in $N_{50-100}$ substantially, bringing it closer to the observed values. While the overestimation of particles above $50 \mathrm{~nm}$ is vastly reduced with OsloAeroSec, there is still a considerable overestimation of the smallest particles (below $\sim 20 \mathrm{~nm}$ ). This indicates that NPF is either too high or too frequent in the model, and this is probably linked to the models having too few larger particles (above $\sim 100 \mathrm{~nm}$ ) and thus a coagulation sink that is too low. Furthermore, the underestimation of the larger particles also leads to less available surface area and a condensation sink that is too low, which may lead to overly high concentrations of $\mathrm{H}_{2} \mathrm{SO}_{4}$ and/or $\mathrm{SOAG}_{\mathrm{LV}}$ and thus nucleation rates that are too high.

Our results also go in line with Lee et al. (2013) and Olenius and Riipinen (2017), who show that a higher cut-off diameter leads to overprediction of the aerosol number concentration. They remark that the most likely explanation is the steady-state assumption used in the parameterizations (in our case Lehtinen et al., 2007). We consider this to be the 


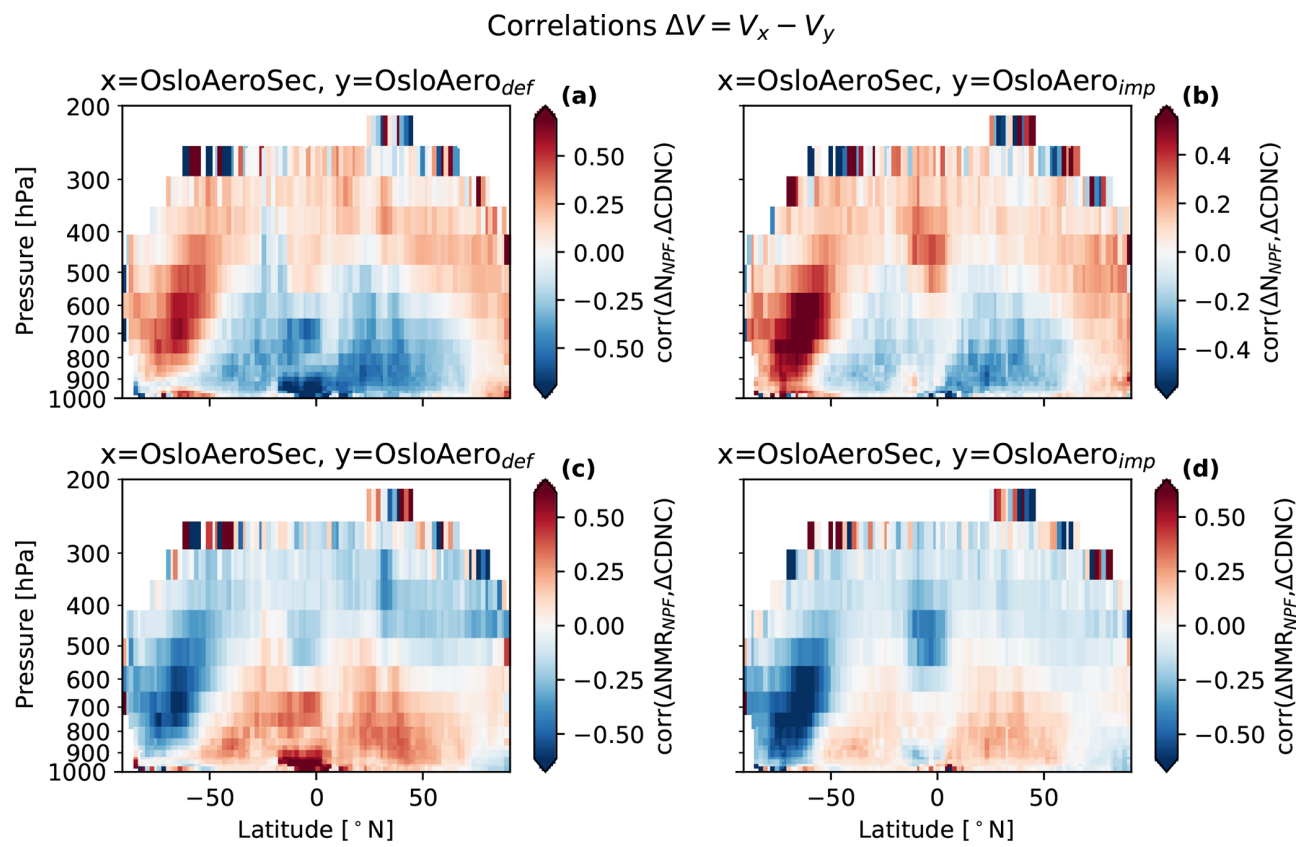

Figure 11. Correlations of the change in CDNC and $N_{\mathrm{NPF}}(\mathbf{a}, \mathbf{b})$ with the number median radius of the NPF particles $(\mathrm{NMR}$ NPF) (c, d). Plots on the left side are for the difference OsloAeroSec - OsloAero def $_{\text {( }}\left(\Delta V=V_{\text {OsloAeroSec }}-V_{\text {OsloAero }_{\text {def }}}\right.$ for variable $\left.V\right)$, and plots on the right are for OsloAeroSec - OsloAero imp.
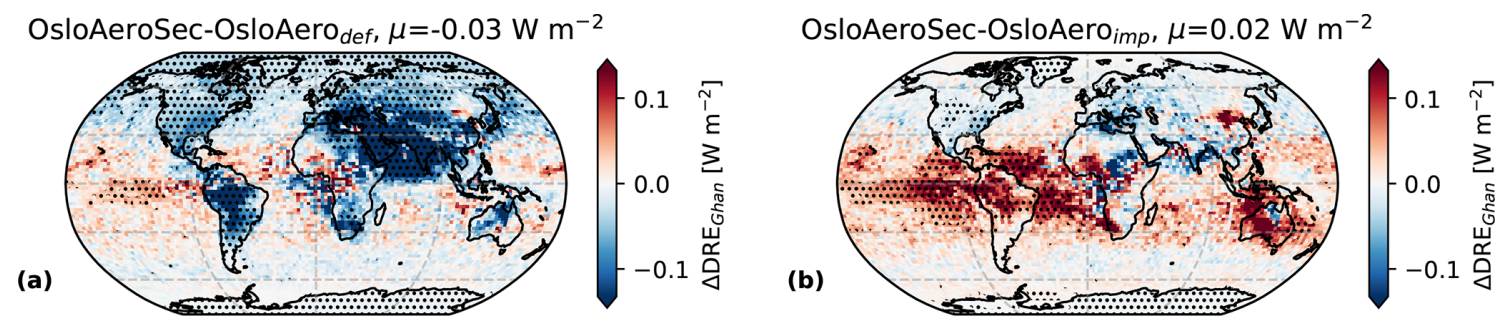

Figure 12. Change in direct aerosol effect for OsloAeroSec minus OsloAero def (a) and OsloAeroSec minus OsloAero imp (b). The direct radiative effect is calculated as recommended by Ghan (2013). Areas where the difference is significant (95\%) are marked with dots.

most likely explanation for the reduction in particles in the modal scheme with OsloAeroSec in our runs as well. In addition, we find that the reduction in number of particles in the modal scheme is largest where the concentration was largest initially and that in clean, remote regions, there is actually an increase in particle number.

In OsloAeroSec we let more organics $\left(\mathrm{SOAG}_{\mathrm{LV}}\right.$ and ELVOC) contribute to growth after $5 \mathrm{~nm}$ than is considered in OsloAero $_{\text {def }}$ and OsloAero ${ }_{\text {imp }}$ (only ELVOC), which is likely why, in the higher atmosphere, OsloAeroSec often produces

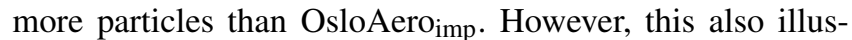
trates the advantage of a sectional scheme, namely that it is possible to differentiate condensation by particle size.

Related to this, we show that the choice of nucleation parameterization, together with the representation of the chemical diurnal variation, has a large influence on the relative contribution of SOA and $\mathrm{H}_{2} \mathrm{SO}_{4}$ to the early growth of the NPF particles. This is especially true when the cut-off di- ameter is high, as in OsloAero def $_{\text {and OsloAero }}$ imp. The reason is that the Riccobono et al. (2014) formulation is non-linear, as opposed to the Paasonen et al. (2010) parameterization, and thus forms proportionately more particles when $\mathrm{H}_{2} \mathrm{SO}_{4}$ concentrations are high. Including the sectional scheme (OsloAeroSec) counteracts this because particles grow for more than one time step and more $\mathrm{SOAG}_{\mathrm{LV}}$ is allowed to contribute to growth.

In sum these effects illustrate that including NPF in global climate models, often with a very simplified chemistry, should be done with care. A parameterization may very well be physically sound, but might still give biased results if it is subjected to unrealistic (diurnal) variability in concentrations. If the cut-off diameter is high and the nucleation parameterization has a super-linear relationship with $\mathrm{H}_{2} \mathrm{SO}_{4}$, the influence of organics on survival to larger sizes might be diminished, resulting in a weaker response to changes in BVOC emissions either in terms of climate feedbacks or 
forcing for e.g. deforestation and afforestation (Sporre et al., 2019, 2020).

As mentioned, the changes introduced by inserting a sectional scheme are heterogeneous in space and time. The number concentration of particles in the modal scheme in general decreases where concentrations were initially high and increases where they were low. A topic for further research is therefore how this would influence the modelled effective radiative forcing from cloud-aerosol interaction (ERFaci). If the OsloAeroSec produces more particles in the cleaner pre-industrial atmosphere and fewer in the present-day atmosphere, it could reduce the ERFaci. Furthermore, the response to both historical and future changes in BVOC emissions may also be different (Sporre et al., 2020) due to a larger role in the early growth.

Furthermore, considering only the station observation comparison and the general decline in $\mathrm{CCN}$-sized number concentration, one might be inclined to think that the same improvement could be achieved by simply reducing the nucleation rate or the survival rate from the Lehtinen et al. (2007) parameterization. However, the fact that the sectional scheme produces more particles in the remote atmosphere shows that such a quick fix would in fact not produce the same climatic effects and could quite possibly create other sensitivities to emission changes.

Interestingly, the cloud-aerosol effects show clear nonlinearities and contradict the simplest assumption that more NPF leads to more CCN, which lead to brighter clouds. The correlation between CDNC and NPF particles $\left(N_{\mathrm{NPF}}\right.$, Fig. 11) rather shows that in polluted regions more NPF results in less CDNC, and the reverse in remote regions. This is due to the fact that when NPF increases, the condensate is spread over more particles, reducing the individual particle size so that fewer are activated as $\mathrm{CCN}$ at a given supersaturation (an effect shown in e.g. Sullivan et al., 2018).

A weakness of the approach of merging a sectional scheme and a modal scheme is that the sectional scheme will grow the particles to the size of the volume median diameter of the particles, but when they are inserted into the modal scheme, these particles are represented with a mode distribution, meaning some of them will "shrink" again, i.e. be on the lower tail of the distribution. However, this is not uniquely a problem for the sectional scheme - any modal representation of aerosol particles includes this effect, and the original parameterization in CAM6-Nor makes the same "error". However, improving the early growth parameterization shines a light on this inconsistency, especially because when we plot the size distribution, the number of small particles becomes the sum of the sectional scheme and the modal approximation.

Furthermore, we include a limited number of processes for the sectional scheme (nucleation, coagulation and condensation, while wet and dry deposition are assumed to be negligible). This is done for simplicity and is also consistent with the processes considered when using Lehtinen et al. (2007) to parameterize the early growth. Including dry and wet deposition might decrease the number concentrations in the model.

The oxidant concentrations in these simulations are read from monthly mean files and used with a superimposed diurnal variation. Any factor that could impact the oxidant concentration - be it changes in chemical sinks or changes to radiation - will not be accounted for. Since new particle formation is very dependent on this chemistry (see e.g. Lee et al., 2019), this inhibits how close the model can come to reality.

In terms of computational cost, we tested running 1 month with standard output fields and the setup described in Sect. 3.1, i.e. active land model and atmosphere, and the computational cost is increased by $\sim 15 \%$ with OsloAeroSec compared to OsloAero def.

\section{Conclusions}

A sectional scheme has been included in the aerosol scheme in CAM6-Nor to explicitly treat the early growth of particles and subsequently feed particles into the pre-existing aerosol scheme. The scheme includes two condensing species, $\mathrm{SOAG}_{\mathrm{LV}}$ and $\mathrm{H}_{2} \mathrm{SO}_{4}$, and five bins. In addition, the diurnal variation in the oxidant concentrations has been improved, and the nucleation parameterization has been updated.

We compare a simulation with the implemented sectional scheme, OsloAeroSec, to two simulations with different versions of the original scheme - one with the default nucleation scheme and oxidant concentrations, OsloAero ${ }_{\text {def }}$, and one in which these are updated to match the sectional scheme, OsloAero ${ }_{\text {imp }}$.

We compare the model output to observations of aerosol concentrations from 2008 and 2009 from 24 stations in Europe (EUSAAR; Asmi et al., 2011a). We find that all versions of the model overestimate the particles smaller than $100 \mathrm{~nm}$, while the sectional scheme shows clear improvement compared to the other two. The largest improvements are in the $N_{50-100}$ in the summer, while changes are insignificant over $100 \mathrm{~nm}$ in diameter.

In general, the sectional scheme reduces the number of particles in the modal scheme near the surface while increasing it further up in the atmosphere and in remote regions.

The decrease in polluted regions is likely due to overestimation in the original scheme due to the high cut-off diameter of the aerosol scheme (Olenius and Riipinen, 2017; Lee et al., 2013).

The relative contributions of $\mathrm{H}_{2} \mathrm{SO}_{4}$ and $\mathrm{SOAG}_{\mathrm{LV}}$ to the early growth of the particles changes between all the model versions. This is due to the complex interplay between in the introduction of diurnal variation of the oxidants, changes to the nucleation equation and the introduction of a sectional scheme. This illustrates that care must be taken when implementing NPF in global models because a highly simplified chemistry may have unintended effects on the sensitivities of NPF to e.g. changing emissions. 
We also analyse the cloud changes and show how the effect of the changes in NPF are heterogeneous in space. An assumption that more particles from NPF lead to more activated $\mathrm{CCN}$ and increased CDNC fails in most regions close to the surface, where the inverse is true. Higher up in the atmosphere and in remote regions, however, the relationship holds.

In general, this study shows that combining a sectional scheme for early growth with a modal scheme for the larger particles is possible and that this treatment of early growth improves the representation in the smaller CCN size range.

Code and data availability. The output data from the simulations used are available for download at https://doi.org/10.11582/2020.00056 (Blichner, 2020a). The model code of NorESM2, release 2.0.1, is available at https://doi.org/10.5281/zenodo.3760870 (Seland et al., 2020a). The code modifications in OsloAeroSec, simulation configurations and setup instructions are released at https://doi.org/10.5281/zenodo.4265057 (Blichner, 2020b). The post-processing code used to produce the figures is available at https://doi.org/10.5281/zenodo.4265033 (Blichner, 2020c). The observational data are available via Asmi et al. (2011a) at https://doi.org/10.1594/PANGAEA.861856 (Asmi et al., 2011b).

Supplement. The supplement related to this article is available online at: https://doi.org/10.5194/gmd-14-3335-2021-supplement.

Author contributions. SMB did the model code development and performed the simulations with NorESM. SMB did the data analysis and wrote the paper. RM and SMB contributed to the idea. SMB, MKS and TKB contributed to discussions regarding the experimental design and data analysis. All authors have contributed to the discussions regarding the paper.

Competing interests. The authors declare that they have no conflict of interest.

Acknowledgements. We would like to thank the EUSAAR project for use of the measurements. Thanks to Diego Aliaga for help and discussions on the data analysis and visualization and to Inger Helene Karset for scientific discussions.

Review statement. This paper was edited by Fiona O'Connor and reviewed by two anonymous referees.

Financial support. This work was financed under the LATICE strategic research initiative funded by the Faculty of Mathematics and Natural Sciences at the University of Oslo. This work has been financed by the Research Council of Norway ( $\mathrm{RCN}$ ) through the NOTUR/Norstore project (NN2806K and NS9066K).

\section{References}

Albrecht, B. A.: Aerosols, Cloud Microphysics, and Fractional Cloudiness, Science, 245, 1227-1230, https://doi.org/10.1126/science.245.4923.1227, 1989.

Anttila, T., Kerminen, V.-M., and Lehtinen, K. E. J.: Parameterizing the Formation Rate of New Particles: The Effect of Nuclei Self-Coagulation, J. Aerosol Sci., 41, 621-636, https://doi.org/10.1016/j.jaerosci.2010.04.008, 2010.

Asmi, A., Wiedensohler, A., Laj, P., Fjaeraa, A.-M., Sellegri, K., Birmili, W., Weingartner, E., Baltensperger, U., Zdimal, V., Zikova, N., Putaud, J.-P., Marinoni, A., Tunved, P., Hansson, H.C., Fiebig, M., Kivekäs, N., Lihavainen, H., Asmi, E., Ulevicius, V., Aalto, P. P., Swietlicki, E., Kristensson, A., Mihalopoulos, N., Kalivitis, N., Kalapov, I., Kiss, G., de Leeuw, G., Henzing, B., Harrison, R. M., Beddows, D., O’Dowd, C., Jennings, S. G., Flentje, H., Weinhold, K., Meinhardt, F., Ries, L., and Kulmala, M.: Number size distributions and seasonality of submicron particles in Europe 2008-2009, Atmos. Chem. Phys., 11, 5505-5538, https://doi.org/10.5194/acp-115505-2011, 2011.

Asmi, A., Wiedensohler, A., Laj, P., Fjaeraa, A.-M., Sellegri, K., Birmili, W., Weingartner, E., Baltensperger, U., Zdimal, V., Zikova, N., Putaud, J.-P., Marinoni, A., Tunved, P., Hansson, H.C., Fiebig, M., Kivekäs, N., Lihavainen, H., Asmi, E., Ulevicius, V., Aalto, P., Swietlicki, E., Kristensson, A., Mihalopoulos, N., Kalivitis, N., Kalapov, I., Kiss, G., de Leeuw, G., Henzing, B., Harrison, R. M., Beddows, D., O’Dowd, C., Jennings, G. S., Flentje, H., Weinhold, K., Meinhardt, F., Ries, L., and Kulmala, M.: EUSAAR Size Distribution Analysis Database, PANGAEA, https://doi.org/10.1594/PANGAEA.861856, 2011 b.

Bentsen, M., Bethke, I., Debernard, J. B., Iversen, T., Kirkevåg, A., Seland, Ø., Drange, H., Roelandt, C., Seierstad, I. A., Hoose, C., and Kristjánsson, J. E.: The Norwegian Earth System Model, NorESM1-M - Part 1: Description and basic evaluation of the physical climate, Geosci. Model Dev., 6, 687-720, https://doi.org/10.5194/gmd-6-687-2013, 2013.

Blichner, S. M.:Data for: Implementing a sectional scheme for early aerosol growth from new particle formation in the Norwegian Earth System Model v2: comparison to observations and climate impacts [Data set], Norstore, https://doi.org/10.11582/2020.00056, 2020a.

Blichner, S. M.: Sarambl/OAS-Code-Setup: Pre-Publication Release, Zenodo [code], https://doi.org/10.5281/zenodo.4265057, 2020b.

Blichner, S. M.: Sarambl/OAS-DEV: Pre-Publication Release, Zenodo [code], https://doi.org/10.5281/zenodo.4265033, 2020c.

Boucher, O., Randall, D., Artaxo, P., Bretherton, C., Feingold, G., Forster, P., Kerminen, V.-M., Kondo, Y., Liao, H., Lohmann, U., Rasch, P., Satheesh, S., Sherwood, S., Stevens, B., and Zhang, X.: Clouds and Aerosols, in: Climate Change 2013: The Physical Science Basis. Contribution of Working Group I to the Fifth Assessment Report of the Intergovernmental Panel on Climate Change, edited by: Stocker, T., Qin, D., Plattner, G.-K., Tignor, M., Allen, S., Boschung, J., Nauels, A., Xia, Y., Bex, V., 
and Midgley, P., Cambridge University Press, Cambridge, UK and New York, NY, USA, 571-658, 2013.

Carslaw, K. S., Lee, L. A., Reddington, C. L., Mann, G. W., and Pringle, K. J.: The Magnitude and Sources of Uncertainty in Global Aerosol, Faraday Discuss., 165, 495-512, https://doi.org/10.1039/C3FD00043E, 2013.

Dall'Osto, M., Beddows, D. C. S., Asmi, A., Poulain, L., Hao, L., Freney, E., Allan, J. D., Canagaratna, M., Crippa, M., Bianchi, F., de Leeuw, G., Eriksson, A., Swietlicki, E., Hansson, H. C., Henzing, J. S., Granier, C., Zemankova, K., Laj, P., Onasch, T., Prevot, A., Putaud, J. P., Sellegri, K., Vidal, M., Virtanen, A., Simo, R., Worsnop, D., O’Dowd, C., Kulmala, M., and Harrison, R. M.: Novel Insights on New Particle Formation Derived from a Pan-European Observing System, Sci. Rep.-UK, 8, 1482, https://doi.org/10.1038/s41598-017-17343-9, 2018.

Danabasoglu, G., Lamarque, J.-F., Bacmeister, J., Bailey, D. A., DuVivier, A. K., Edwards, J., Emmons, L. K., Fasullo, J., Garcia, R., Gettelman, A., Hannay, C., Holland, M. M., Large, W. G., Lauritzen, P. H., Lawrence, D. M., Lenaerts, J. T. M., Lindsay, K., Lipscomb, W. H., Mills, M. J., Neale, R., Oleson, K. W., Otto-Bliesner, B., Phillips, A. S., Sacks, W., Tilmes, S., van Kampenhout, L., Vertenstein, M., Bertini, A., Dennis, J., Deser, C., Fischer, C., Fox-Kemper, B., Kay, J. E., Kinnison, D., Kushner, P. J., Larson, V. E., Long, M. C., Mickelson, S., Moore, J. K., Nienhouse, E., Polvani, L., Rasch, P. J., and Strand, W. G.: The Community Earth System Model Version 2 (CESM2), J. Adv. Model. Earth Sy., 12, e2019MS001916, https://doi.org/10.1029/2019MS001916, 2020

Dunne, E. M., Gordon, H., Kürten, A., Almeida, J., Duplissy, J., Williamson, C., Ortega, I. K., Pringle, K. J., Adamov, A., Baltensperger, U., Barmet, P., Benduhn, F., Bianchi, F., Breitenlechner, M., Clarke, A., Curtius, J., Dommen, J., Donahue, N. M., Ehrhart, S., Flagan, R. C., Franchin, A., Guida, R., Hakala, J., Hansel, A., Heinritzi, M., Jokinen, T., Kangasluoma, J., Kirkby, J., Kulmala, M., Kupc, A., Lawler, M. J., Lehtipalo, K., Makhmutov, V., Mann, G., Mathot, S., Merikanto, J., Miettinen, P., Nenes, A., Onnela, A., Rap, A., Reddington, C. L. S., Riccobono, F., Richards, N. A. D., Rissanen, M. P., Rondo, L., Sarnela, N., Schobesberger, S., Sengupta, K., Simon, M., Sipilä, M., Smith, J. N., Stozkhov, Y., Tomé, A., Tröstl, J., Wagner, P. E., Wimmer, D., Winkler, P. M., Worsnop, D. R., and Carslaw, K. S.: Global Atmospheric Particle Formation from CERN CLOUD Measurements, Science, 354, 1119-1124, https://doi.org/10.1126/science.aaf2649, 2016.

European Centre for Medium-range Weather Forecast (ECMWF): The ERA-Interim reanalysis dataset, Copernicus Climate Change Service (C3S), available at: https://www.ecmwf.int/en/forecasts/datasets/archive-datasets/ reanalysis-datasets/era-interim (last access: 14 August 2020), 2011.

Emmons, L. K., Walters, S., Hess, P. G., Lamarque, J.-F., Pfister, G. G., Fillmore, D., Granier, C., Guenther, A., Kinnison, D., Laepple, T., Orlando, J., Tie, X., Tyndall, G., Wiedinmyer, C., Baughcum, S. L., and Kloster, S.: Description and evaluation of the Model for Ozone and Related chemical Tracers, version 4 (MOZART-4), Geosci. Model Dev., 3, 43-67, https://doi.org/10.5194/gmd-3-43-2010, 2010.
Ghan, S. J.: Technical Note: Estimating aerosol effects on cloud radiative forcing, Atmos. Chem. Phys., 13, 9971-9974, https://doi.org/10.5194/acp-13-9971-2013, 2013.

Gordon, H., Sengupta, K., Rap, A., Duplissy, J., Frege, C., Williamson, C., Heinritzi, M., Simon, M., Yan, C., Almeida, J., Tröstl, J., Nieminen, T., Ortega, I. K., Wagner, R., Dunne, E. M., Adamov, A., Amorim, A., Bernhammer, A.-K., Bianchi, F., Breitenlechner, M., Brilke, S., Chen, X., Craven, J. S., Dias, A., Ehrhart, S., Fischer, L., Flagan, R. C., Franchin, A., Fuchs, C., Guida, R., Hakala, J., Hoyle, C. R., Jokinen, T., Junninen, H., Kangasluoma, J., Kim, J., Kirkby, J., Krapf, M., Kürten, A., Laaksonen, A., Lehtipalo, K., Makhmutov, V., Mathot, S., Molteni, U., Monks, S. A., Onnela, A., Peräkylä, O., Piel, F., Petäjä, T., Praplan, A. P., Pringle, K. J., Richards, N. A. D., Rissanen, M. P., Rondo, L., Sarnela, N., Schobesberger, S., Scott, C. E., Seinfeld, J. H., Sharma, S., Sipilä, M., Steiner, G., Stozhkov, Y., Stratmann, F., Tomé, A., Virtanen, A., Vogel, A. L., Wagner, A. C., Wagner, P. E., Weingartner, E., Wimmer, D., Winkler, P. M., Ye, P., Zhang, X., Hansel, A., Dommen, J., Donahue, N. M., Worsnop, D. R., Baltensperger, U., Kulmala, M., Curtius, J., and Carslaw, K. S.: Reduced Anthropogenic Aerosol Radiative Forcing Caused by Biogenic New Particle Formation, P. Natl. Acad. Sci. USA, 113, 12053-12058, https://doi.org/10.1073/pnas.1602360113, 2016.

Gordon, H., Kirkby, J., Baltensperger, U., Bianchi, F., Breitenlechner, M., Curtius, J., Dias, A., Dommen, J., Donahue, N. M., Dunne, E. M., Duplissy, J., Ehrhart, S., Flagan, R. C., Frege, C., Fuchs, C., Hansel, A., Hoyle, C. R., Kulmala, M., Kürten, A., Lehtipalo, K., Makhmutov, V., Molteni, U., Rissanen, M. P., Stozkhov, Y., Tröstl, J., Tsagkogeorgas, G., Wagner, R., Williamson, C., Wimmer, D., Winkler, P. M., Yan, C., and Carslaw, K. S.: Causes and Importance of New Particle Formation in the Present-Day and Preindustrial Atmospheres: Causes and Role of New Particle Formation, J. Geophys. Res.-Atmos. 122, 8739-8760, https://doi.org/10.1002/2017JD026844, 2017.

Guenther, A. B., Jiang, X., Heald, C. L., Sakulyanontvittaya, T., Duhl, T., Emmons, L. K., and Wang, X.: The Model of Emissions of Gases and Aerosols from Nature version 2.1 (MEGAN2.1): an extended and updated framework for modeling biogenic emissions, Geosci. Model Dev., 5, 1471-1492, https://doi.org/10.5194/gmd-5-1471-2012, 2012.

Hurrell, J. W., Hack, J. J., Shea, D., Caron, J. M., and Rosinski, J.: A New Sea Surface Temperature and Sea Ice Boundary Dataset for the Community Atmosphere Model, J. Climate, 21, 5145-5153, https://doi.org/10.1175/2008JCLI2292.1, 2008.

Iversen, T., Bentsen, M., Bethke, I., Debernard, J. B., Kirkevåg, A., Seland, Ø., Drange, H., Kristjansson, J. E., Medhaug, I., Sand, M., and Seierstad, I. A.: The Norwegian Earth System Model, NorESM1-M - Part 2: Climate response and scenario projections, Geosci. Model Dev., 6, 389-415, https://doi.org/10.5194/gmd-6-389-2013, 2013.

Jacobson, M. Z.: Development and Application of a New Air Pollution Modeling System - Part III. Aerosol-Phase Simulations, Atmos. Environ., 31, 587-608, https://doi.org/10.1016/S13522310(96)00201-4, 1997.

Jacobson, M. Z.: Fundamentals of Atmospheric Modeling, 2nd Edn., Cambridge University Press, Cambridge, https://doi.org/10.1017/CBO9781139165389, 2005. 
Karset, I. H. H.: Enhancing the Confidence in Estimates of Effective Radiative Forcing by Aerosol through Improved Global Modelling, PhD thesis, University of Oslo, Oslo, 2020.

Karset, I. H. H., Berntsen, T. K., Storelvmo, T., Alterskjær, K., Grini, A., Olivié, D., Kirkevåg, A., Seland, Ø., Iversen, T., and Schulz, M.: Strong impacts on aerosol indirect effects from historical oxidant changes, Atmos. Chem. Phys., 18, 7669-7690, https://doi.org/10.5194/acp-18-7669-2018, 2018.

Kerminen, V.-M. and Kulmala, M.: Analytical Formulae Connecting the "Real" and the "Apparent" Nucleation Rate and the Nuclei Number Concentration for Atmospheric Nucleation Events, J. Aerosol Sci., 33, 609-622, https://doi.org/10.1016/S00218502(01)00194-X, 2002.

Kerminen, V.-M., Anttila, T., Lehtinen, K., and Kulmala, M.: Parameterization for Atmospheric New-Particle Formation: Application to a System Involving Sulfuric Acid and Condensable Water-Soluble Organic Vapors, Aerosol Sci. Tech., 38, 10011008, https://doi.org/10.1080/027868290519085, 2004.

Kerminen, V.-M., Paramonov, M., Anttila, T., Riipinen, I., Fountoukis, C., Korhonen, H., Asmi, E., Laakso, L., Lihavainen, H., Swietlicki, E., Svenningsson, B., Asmi, A., Pandis, S. N., Kulmala, M., and Petäjä, T.: Cloud condensation nuclei production associated with atmospheric nucleation: a synthesis based on existing literature and new results, Atmos. Chem. Phys., 12, 1203712059, https://doi.org/10.5194/acp-12-12037-2012, 2012.

Kerminen, V.-M., Chen, X., Vakkari, V., Petäjä, T., Kulmala, M., and Bianchi, F.: Atmospheric New Particle Formation and Growth: Review of Field Observations, Environ. Res. Lett., 13, 103003, https://doi.org/10.1088/1748-9326/aadf3c, 2018.

Kirkby, J., Duplissy, J., Sengupta, K., Frege, C., Gordon, H. Williamson, C., Heinritzi, M., Simon, M., Yan, C., Almeida, J., Tröstl, J., Nieminen, Ortega, T., Wagner, R., Adamov, A., Amorim, A., Bernhammer, A., Bianchi, F., Breitenlechner, M., Brilke, S., Chen, X., Craven, J., Dias, A., Ehrhart, S., Flagan, R. C., Franchin, A., Fuchs, C., Guida, R., Hakala, J., Hoyle, C. R., Jokinen, T., Junninen, H. Kangasluoma, J., Kim, J., Krapf, M. Kürten, A., Laaksonen, A., Lehtipalo, K., Makhmutov, V., Mathot, S., Molteni, U., Onnela, A., Peräkylä, O., Piel, F., Petäjä, T., Praplan, A. P., Pringle, K., Rap, A., Richards, N., Riipinen, I., Rissanen, M. P., Rondo, L., Sarnela, N., Schobesberger, S., Scott, C., Seinfeld, J. H., Sipilä, M., Steiner, G., Stozhkov, Y., Stratmann, F., Tomé, A., Virtanen, A., Vogel, A., Wagner, A., Wagner, P., Weingartner, E., Wimmer, D., Winkler, P., Ye, P., Zhang, X., Hansel, A., Dommen, J., Donahue, N. M., Worsnop, D., Baltensperger, U., Kulmala, M., Carslaw, K. S., and Curtius, J.: Ion-Induced Nucleation of Pure Biogenic Particles, Nature, 476, 429-433, https://doi.org/10.1038/nature17953, 2016.

Kirkevåg, A., Iversen, T., Seland, Ø., Hoose, C., Kristjánsson, J. E., Struthers, H., Ekman, A. M. L., Ghan, S., Griesfeller, J., Nilsson, E. D., and Schulz, M.: Aerosol-climate interactions in the Norwegian Earth System Model - NorESM1-M, Geosci. Model Dev., 6, 207-244, https://doi.org/10.5194/gmd-6-2072013, 2013.

Kirkevåg, A., Grini, A., Olivié, D., Seland, Ø., Alterskjær, K., Hummel, M., Karset, I. H. H., Lewinschal, A., Liu, X., Makkonen, R., Bethke, I., Griesfeller, J., Schulz, M., and Iversen, T.: A production-tagged aerosol module for Earth system models, OsloAero5.3 - extensions and updates for CAM5.3-Oslo, Geosci. Model Dev., 11, 3945-3982, https://doi.org/10.5194/gmd-11-3945-2018, 2018.

Kokkola, H., Korhonen, H., Lehtinen, K. E. J., Makkonen, R., Asmi, A., Järvenoja, S., Anttila, T., Partanen, A.-I., Kulmala, M., Järvinen, H., Laaksonen, A., and Kerminen, V.-M.: SALSA - a Sectional Aerosol module for Large Scale Applications, Atmos. Chem. Phys., 8, 2469-2483, https://doi.org/10.5194/acp-8-24692008, 2008.

Kooperman, G. J., Pritchard, M. S., Ghan, S. J., Wang, M., Somerville, R. C. J., and Russell, L. M.: Constraining the Influence of Natural Variability to Improve Estimates of Global Aerosol Indirect Effects in a Nudged Version of the Community Atmosphere Model 5, J. Geophys. Res.-Atmos., 117, D23204, https://doi.org/10.1029/2012JD018588, 2012.

Lawrence, D. M., Fisher, R. A., Koven, C. D., Oleson, K. W., Swenson, S. C., Bonan, G., Collier, N., Ghimire, B., van Kampenhout, L., Kennedy, D., Kluzek, E., Lawrence, P. J., Li, F., Li, H., Lombardozzi, D., Riley, W. J., Sacks, W. J., Shi, M., Vertenstein, M., Wieder, W. R., Xu, C., Ali, A. A., Badger, A. M., Bisht, G., van den Broeke, M., Brunke, M. A., Burns, S. P., Buzan, J., Clark, M., Craig, A., Dahlin, K., Drewniak, B., Fisher, J. B., Flanner, M., Fox, A. M., Gentine, P., Hoffman, F., Keppel-Aleks, G., Knox, R., Kumar, S., Lenaerts, J., Leung, L. R., Lipscomb, W. H., Lu, Y., Pandey, A., Pelletier, J. D., Perket, J., Randerson, J. T., Ricciuto, D. M., Sanderson, B. M., Slater, A., Subin, Z. M., Tang, J., Thomas, R. Q., Martin, M. V., and Zeng, X.: The Community Land Model Version 5: Description of New Features, Benchmarking, and Impact of Forcing Uncertainty, J. Adv. Model. Earth Sy., 11, 4245-4287, https://doi.org/10.1029/2018MS001583, 2019.

Lee, S.-H., Gordon, H., Yu, H., Lehtipalo, K., Haley, R., Li, Y., and Zhang, R.: New Particle Formation in the Atmosphere: From Molecular Clusters to Global Climate, J. Geophys. Res.-Atmos., 124, 7098-7146, https://doi.org/10.1029/2018JD029356, 2019.

Lee, Y. H., Pierce, J. R., and Adams, P. J.: Representation of nucleation mode microphysics in a global aerosol model with sectional microphysics, Geosci. Model Dev., 6, 1221-1232, https://doi.org/10.5194/gmd-6-1221-2013, 2013.

Lehtinen, K. E. J., Dal Maso, M., Kulmala, M., and Kerminen, V.-M.: Estimating Nucleation Rates from Apparent Particle Formation Rates and Vice Versa: Revised Formulation of the Kerminen-Kulmala Equation, J. Aerosol Sci., 38, 988-994, https://doi.org/10.1016/j.jaerosci.2007.06.009, 2007

Liu, X., Penner, J. E., and Herzog, M.: Global Modeling of Aerosol Dynamics: Model Description, Evaluation, and Interactions between Sulfate and Nonsulfate Aerosols, J. Geophys. Res.Atmos., 110, D18206, https://doi.org/10.1029/2004JD005674, 2005.

Makkonen, R., Seland, Ø., Kirkevåg, A., Iversen, T., and Kristjánsson, J. E.: Evaluation of aerosol number concentrations in NorESM with improved nucleation parameterization, Atmos. Chem. Phys., 14, 5127-5152, https://doi.org/10.5194/acp-145127-2014, 2014.

Mamali, D., Mikkilä, J., Henzing, B., Spoor, R., Ehn, M., Petäjä, T., Russchenberg, H., and Biskos, G.: Long-Term Observations of the Background Aerosol at Cabauw, The Netherlands, Sci. Total Environ., 625, 752-761, https://doi.org/10.1016/j.scitotenv.2017.12.136, 2018. 
Mann, G. W., Carslaw, K. S., Spracklen, D. V., Ridley, D. A., Manktelow, P. T., Chipperfield, M. P., Pickering, S. J., and Johnson, C. E.: Description and evaluation of GLOMAP-mode: a modal global aerosol microphysics model for the UKCA composition-climate model, Geosci. Model Dev., 3, 519-551, https://doi.org/10.5194/gmd-3-519-2010, 2010.

Neale, R. B., Gettelman, A., Park, S., Chen, C.-c., Lauritzen, P. H., Williamson, D. L., Conley, A. J., Kinnison, D., Marsh, D., Smith, A. K., Vitt, F., Garcia, R., Lamarque, J.-f., Mills, M., Tilmes, S., Morrison, H., Cameron-smith, P., Collins, W. D., Iacono, M. J., Easter, R. C., Liu, X., Ghan, S. J., Rasch, P. J., and a Taylor, M.: Description of the NCAR Community Atmosphere Model (CAM 5.0), NCAR Technical Notes, Ncar/Tn-464+Str, 214 pp., https://doi.org/10.5065/D6N877R0, 2012.

Olenius, T. and Riipinen, I.: Molecular-Resolution Simulations of New Particle Formation: Evaluation of Common Assumptions Made in Describing Nucleation in Aerosol Dynamics Models, Aerosol Sci. Tech., 51, 397-408, https://doi.org/10.1080/02786826.2016.1262530, 2017.

Paasonen, P., Nieminen, T., Asmi, E., Manninen, H. E., Petäjä, T., Plass-Dülmer, C., Flentje, H., Birmili, W., Wiedensohler, A., Hõrrak, U., Metzger, A., Hamed, A., Laaksonen, A., Facchini, M. C., Kerminen, V.-M., and Kulmala, M.: On the roles of sulphuric acid and low-volatility organic vapours in the initial steps of atmospheric new particle formation, Atmos. Chem. Phys., 10, 11223-11242, https://doi.org/10.5194/acp-10-112232010, 2010.

Riccobono, F., Schobesberger, S., Scott, C. E., Dommen, J., Ortega, I. K., Rondo, L., Almeida, J., Amorim, A., Bianchi, F., Breitenlechner, M., David, A., Downard, A., Dunne, E. M., Duplissy, J., Ehrhart, S., Flagan, R. C., Franchin, A., Hansel, A., Junninen, H., Kajos, M., Keskinen, H., Kupc, A., Kürten, A., Kvashin, A. N., Laaksonen, A., Lehtipalo, K., Makhmutov, V., Mathot, S., Nieminen, T., Onnela, A., Petäjä, T., Praplan, A. P., Santos, F. D., Schallhart, S., Seinfeld, J. H., Sipilä, M., Spracklen, D. V., Stozhkov, Y., Stratmann, F., Tomé, A., Tsagkogeorgas, G., Vaattovaara, P., Viisanen, Y., Vrtala, A., Wagner, P. E., Weingartner, E., Wex, H., Wimmer, D., Carslaw, K. S., Curtius, J., Donahue, N. M., Kirkby, J., Kulmala, M., Worsnop, D. R., and Baltensperger, U.: Oxidation Products of Biogenic Emissions Contribute to Nucleation of Atmospheric Particles, Science, 344, 717-721, https://doi.org/10.1126/science.1243527, 2014.

Riipinen, I., Pierce, J. R., Yli-Juuti, T., Nieminen, T., Häkkinen, S., Ehn, M., Junninen, H., Lehtipalo, K., Petäjä, T., Slowik, J., Chang, R., Shantz, N. C., Abbatt, J., Leaitch, W. R., Kerminen, V.-M., Worsnop, D. R., Pandis, S. N., Donahue, N. M., and Kulmala, M.: Organic condensation: a vital link connecting aerosol formation to cloud condensation nuclei (CCN) concentrations, Atmos. Chem. Phys., 11, 3865-3878, https://doi.org/10.5194/acp-11-3865-2011, 2011.

Schutgens, N. A. J. and Stier, P.: A pathway analysis of global aerosol processes, Atmos. Chem. Phys., 14, 11657-11686, https://doi.org/10.5194/acp-14-11657-2014, 2014.

Seinfeld, J. H. and Pandis, S. N.: Atmospheric Chemistry and Physics from Air Pollution to Climate Change, John Wiley, New York, 1998.

Seland, Ø., Iversen, T., KirkevåG, A., and Storelvmo, T.: AerosolClimate Interactions in the CAM-Oslo Atmospheric GCM and Investigation of Associated Basic Shortcomings, Tellus A, 60, 459-491, https://doi.org/10.1111/j.1600-0870.2008.00318.x, 2008.

Seland, Ø., Bentsen, M., Olivié, D., Toniazzo, T., Gjermundsen, A., Graff, L. S., Debernard, J. B., Gupta, A. K., He, Y., Kirkevåg, A., Schwinger, J., Tjiputra, J., Aas, K. S., Bethke, I., Fan, Y., Gao, S., Griesfeller, J., Grini, A., Guo, C., Ilicak, M., Karset, I. H. H., Landgren, O., Liakka, J., Moree, A., Moseid, K. O., Nummelin, A., Spensberger, C., Tang, H., Zhang, Z., Heinze, C., Iversen, T., and Schulz, M.: NorESM2 Source Code as Used for CMIP6 Simulations, Zenodo [code], https://doi.org/10.5281/zenodo.3760870, 2020a.

Seland, Ø., Bentsen, M., Olivié, D., Toniazzo, T., Gjermundsen, A., Graff, L. S., Debernard, J. B., Gupta, A. K., He, Y.C., Kirkevåg, A., Schwinger, J., Tjiputra, J., Aas, K. S., Bethke, I., Fan, Y., Griesfeller, J., Grini, A., Guo, C., Ilicak, M., Karset, I. H. H., Landgren, O., Liakka, J., Moseid, K. O., Nummelin, A., Spensberger, C., Tang, H., Zhang, Z., Heinze, C., Iversen, T., and Schulz, M.: Overview of the Norwegian Earth System Model (NorESM2) and key climate response of CMIP6 DECK, historical, and scenario simulations, Geosci. Model Dev., 13, 6165-6200, https://doi.org/10.5194/gmd-136165-2020, 2020b.

Semeniuk, K. and Dastoor, A.: Current State of Aerosol Nucleation Parameterizations for Air-Quality and Climate Modeling, Atmos. Environ., 179, 77-106, https://doi.org/10.1016/j.atmosenv.2018.01.039, 2018.

Sporre, M. K., Blichner, S. M., Karset, I. H. H., Makkonen, R., and Berntsen, T. K.: BVOC-aerosol-climate feedbacks investigated using NorESM, Atmos. Chem. Phys., 19, 4763-4782, https://doi.org/10.5194/acp-19-4763-2019, 2019.

Sporre, M. K., Blichner, S. M., Schrödner, R., Karset, I. H. H., Berntsen, T. K., van Noije, T., Bergman, T., O’Donnell, D., and Makkonen, R.: Large difference in aerosol radiative effects from BVOC-SOA treatment in three Earth system models, Atmos. Chem. Phys., 20, 8953-8973, https://doi.org/10.5194/acp20-8953-2020, 2020.

Spracklen, D. V., Pringle, K. J., Carslaw, K. S., Chipperfield, M. P., and Mann, G. W.: A global off-line model of size-resolved aerosol microphysics: I. Model development and prediction of aerosol properties, Atmos. Chem. Phys., 5, 2227-2252, https://doi.org/10.5194/acp-5-2227-2005, 2005.

Stier, P., Feichter, J., Kinne, S., Kloster, S., Vignati, E., Wilson, J., Ganzeveld, L., Tegen, I., Werner, M., Balkanski, Y., Schulz, M., Boucher, O., Minikin, A., and Petzold, A.: The aerosol-climate model ECHAM5-HAM, Atmos. Chem. Phys., 5, 1125-1156, https://doi.org/10.5194/acp-5-1125-2005, 2005.

Sullivan, R. C., Crippa, P., Matsui, H., Leung, L. R., Zhao, C., Thota, A., and Pryor, S. C.: New Particle Formation Leads to Cloud Dimming, npj Climate and Atmospheric Science, 1, 1-9, https://doi.org/10.1038/s41612-018-0019-7, 2018.

Tie, X., Brasseur, G., Emmons, L., Horowitz, L., and Kinnison, D.: Effects of Aerosols on Tropospheric Oxidants: A Global Model Study, J. Geophys. Res.-Atmos., 106, 22931-22964, https://doi.org/10.1029/2001JD900206, 2001.

Tröstl, J., Chuang, W. K., Gordon, H., Heinritzi, M., Yan, C., Molteni, U., Ahlm, L., Frege, C., Bianchi, F., Wagner, R., Simon, M., Lehtipalo, K., Williamson, C., Craven, J. S., Duplissy, J., Adamov, A., Almeida, J., Bernhammer, A.-K., Breit- 
enlechner, M., Brilke, S., Dias, A., Ehrhart, S., Flagan, R. C., Franchin, A., Fuchs, C., Guida, R., Gysel, M., Hansel, A., Hoyle, C. R., Jokinen, T., Junninen, H., Kangasluoma, J., Keskinen, H., Kim, J., Krapf, M., Kürten, A., Laaksonen, A., Lawler, M., Leiminger, M., Mathot, S., Möhler, O., Nieminen, T., Onnela, A., Petäjä, T., Piel, F. M., Miettinen, P., Rissanen, M. P., Rondo, L., Sarnela, N., Schobesberger, S., Sengupta, K., Sipilä, M., Smith, J. N., Steiner, G., Tomè, A., Virtanen, A., Wagner, A. C., Weingartner, E., Wimmer, D., Winkler, P. M., Ye, P., Carslaw, K. S., Curtius, J., Dommen, J., Kirkby, J., Kulmala, M., Riipinen, I., Worsnop, D. R., Donahue, N. M., and Baltensperger, U.: The Role of Low-Volatility Organic Compounds in Initial Particle Growth in the Atmosphere, Nature, 533, 527531, https://doi.org/10.1038/nature18271, 2016.

Twomey, S.: Pollution and the Planetary Albedo, Atmos. Environ., 8, 1251-1256, https://doi.org/10.1016/0004-6981(74)90004-3, 1974.

Vehkamäki, H., Kulmala, M., Napari, I., Lehtinen, K. E. J., Timmreck, C., Noppel, M., and Laaksonen, A.: An Improved Parameterization for Sulfuric Acid-Water Nucleation Rates for Tropospheric and Stratospheric Conditions, J. Geophys. Res., 107, 4622, https://doi.org/10.1029/2002JD002184, 2002.
Vignati, E., Wilson, J., and Stier, P.: M7: An Efficient Size-Resolved Aerosol Microphysics Module for Large-Scale Aerosol Transport Models: Aerosol Microphysics Module, J. Geophys. Res.Atmos., 109, D22202, https://doi.org/10.1029/2003JD004485, 2004.

Westervelt, D. M., Pierce, J. R., Riipinen, I., Trivitayanurak, W., Hamed, A., Kulmala, M., Laaksonen, A., Decesari, S., and Adams, P. J.: Formation and growth of nucleated particles into cloud condensation nuclei: model-measurement comparison, Atmos. Chem. Phys., 13, 7645-7663, https://doi.org/10.5194/acp13-7645-2013, 2013.

Westervelt, D. M., Pierce, J. R., and Adams, P. J.: Analysis of feedbacks between nucleation rate, survival probability and cloud condensation nuclei formation, Atmos. Chem. Phys., 14, 55775597, https://doi.org/10.5194/acp-14-5577-2014, 2014. 